\title{
510(K) ClEARANCE: OPPORTUNITIES TO INCENTIVIZE MEDICAL DEVICE SAFETY THROUGH COMPARATIVE EFFECTIVENESS RESEARCH
}

\author{
Amanda Swanson*
}

ABSTRACT

I. INTRODUCTION

II. FEDERAL REgUlation OF MEDiCAL DEVICE SAFETY AND

EFFICACY

A. History ......................................................... 120

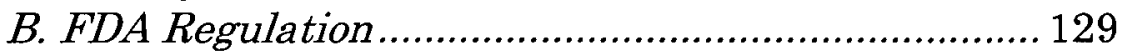

1. Rulemaking and Guidance.............................. 129

2. Reporting and Postmarket Surveillance .............. 134

3. Enforcement Powers....................................... 142

a. Administrative .............................................. 142

b. Judicial..................................................... 145

C. When the Regulatory Process Fails: The Tort System ........................................................ 147

III. Proposals to FIX THE FlaWS IN THE System ............ 152

A. Institute of Medicine: A New Regulatory System for 510(k) Devices .................................................. 152

B. Use of Comparative Effectiveness Research by the

Government as Payer........................................... 156

IV. CoNCLUSION ......................................................... 172

\section{AbstraCT}

The Food and Drug Administration's 510(k) clearance process, which clears medical devices for marketing based on their similarity to devices already available on the market, has remained almost entirely unchanged since its creation in 1976. Thirty-five years later, the Institute of

* Amanda Swanson is an Illinois licensed attorney and received her LL.M. in health law and J.D. from Loyola University Chicago School of Law. She currently works for the City of Chicago Department of Law, and can be reached at aeswans@gmail.com. 
Medicine was charged with evaluating this process, and concluded that it does not sufficiently protect patients from unsafe medical devices. Although the IOM proposed creating a new regulatory framework utilizing more premarket and postmarket evaluation of scientific evidence of safety and effectiveness, the feasibility of this is limited by the FDA's resource constraints. Instead, this article proposes that the best solution is for the federal government, in its capacity as payer, to use comparative effectiveness research in its coverage determinations. This would maintain the efficiency of the $510(\mathrm{k})$ clearance process without sacrificing patient safety, while also shifting the responsibility for increased surveillance of $510(\mathrm{k})$ devices from the FDA to other agencies, fostering innovation and keeping the U.S. a competitive market in the medical device industry.

\section{INTRODUCTION}

After a string of adverse events resulting from the use of faulty heart-defibrillator wires, ${ }^{1}$ three senators, on March 15,2012 , introduced a bill in Congress that aims to improve the Food and Drug Administration's (FDA) oversight of medical devices, entitled the Ensuring Safe Medical Devices for Patients Act. ${ }^{2}$ This bill intends to accomplish this through increasing postmarket surveillance and risk identification of medical devices, and also creating a unique device identification system, which would require implantable devices to carry a unique number that could be used to track the device through the distribution chain. ${ }^{3}$ The goal is to protect patients and ensure that unsafe

1 See Thomas Burton, FDA in Hot Seat on Safety: Doctors Want Agency to Better Gauge Risks of Heart Devices, WALL ST. J., Apr. 9, 2012, http://online.wsj.com/article/SB10001424052702303772904577333 941715666550.html (last visited Nov. 25, 2012).

2 Ensuring Safe Medical Devices for Patients Act, S. 2193, 112th Cong. (2012), available at http://www.gpo.gov/fdsys/pkg/BILLS-112s 2193is/pdf/BILLS-112s2193is.pdf.

$3 \quad I d$. at $\S 2$. 
and/or defective devices can be quickly identified and the products removed from the market. ${ }^{4}$ Doctors are also pushing for increases in reporting requirements for medical devices, and the FDA has revealed plans to improve their safety monitoring programs. ${ }^{5}$ It seems there is a consensus that more can be done to ensure the safety of medical devices available in the United States market.

Even in light of this awareness, one aspect of medical device regulation has remained almost entirely unchanged since its creation in 1976: the $510(\mathrm{k})$ clearance process. Through this process, devices are cleared for marketing (not granted an approval based upon considerations of safety and effectiveness) based on their clinical similarity to devices already available on the market at the inception of this process. ${ }^{6}$ In September 2009, the FDA charged the Institute of Medicine (IOM) with reviewing this clearance process and determining if it optimally promotes innovation while protecting the public's health, and if not, what changes would improve the process' ability to achieve these goals. $^{7}$

This article will provide an overview of the FDA's current regulatory and approval processes for medical devices and will discuss the determinations made by the IOM in its evaluation of the $510(\mathrm{k})$ clearance process. Then the recommendations presented in the IOM report and their likelihood to succeed in improving patient safety will be

4 Press Release, Office of Senator Jeff Merkley, Senators Introduce Bipartisan Effort to Make Medical Devices Safer: The Ensuring Safe Medical Devices for Patients Act Would Implement Long Overdue Reforms and Help Save Lives (March 15, 2012), available at http://www.merkley.senate.gov/newsroom/press/release/?id=63dd8e2dbf9a-491c-bfc2-0a33a5096bf7 (last visited Nov. 25, 2012). The unique device identification system was authorized by the FDA Amendments Act of 2007, but it has yet to be implemented. FDA Amendments Act of 2007, Pub. L. No. 110-85, § 226, 121 Stat. 823, 854 (2007), available at http://www.gpo.gov/fdsys/pkg/PLAW-110publ85/pdf/PLAW-110publ85. pdf.

5 Burton, supra note 1.

6 INST. OF MED., MEDiCAL DeVICES AND THE PUBlic's HeAlth: THE FDA 510(K) CleARANCE PROCESS AT 35 YeARS 15 (2011) [hereinafter IOM REPORT].

$7 \quad$ Id. at 16. 
analyzed. Finally, this paper will conclude that, although the IOM's recommendations will provide a large step in the right direction, more must be done to ensure the safety of the medical devices on the market. It will be proposed that the best way to ensure the safety and efficacy of medical devices is for the federal government, in its capacity as payer under federal health programs, to compare the effectiveness of devices and medical interventions already available to new devices ready to enter the market and use this information in determining whether or not devices will be covered under either program. In this way, the U.S. will not fall behind other nations with regard to availability of cutting edge technologies in medicine by overburdening the FDA with extensive evaluations of devices. Instead, device manufacturers and patients both will benefit from prompt availability of reasonably safe medical devices, the assured continuation of research into the comparative effectiveness of new devices, and the availability of this information to guide medical decision making and ensure patients receive the safest and most effective treatments available.

\section{Federal Regulation of MEdicAL DeVICE SAFETy AND EFFICACY}

\section{A. History}

The first significant action of Congress in the realm of public health and safety occurred in 1906 when it passed the Pure Food and Drug Act. ${ }^{8}$ This Act prohibited the manufacture and interstate shipment of adulterated, misbranded, or harmful foods, drugs, and liquors. ${ }^{9}$ In 1938 federal regulation was expanded to cover misbranded or adulterated cosmetics and medical devices as well through the passage of the Federal Food, Drug and Cosmetic Act (FDCA). ${ }^{10}$ The FDCA prohibited the adulteration or

8 The Federal Food and Drugs Act of 1906, 21 U.S.C. $\$ 1$ (repealed 1938).

$9 \quad I d$.

10 The Federal Food, Drug and Cosmetic Act of 1938, 21 U.S.C. $\S$ 301 (1938). 
misbranding of medical devices, and gave the FDA authority to inspect manufacturers of medical devices. ${ }^{11}$ However, although the FDCA established a premarket approval process based on evaluations of safety for drugs, it did not regulate the ability of new medical devices to enter the market. Instead, the FDA could only seize dangerous devices on the market and rely on injunction actions to prevent dangerous devices from returning to the market. ${ }^{12}$ For many decades this Act and its corresponding regulations constituted the parameters of federal oversight of the medical device industry. In the 1970s several devices began to draw the attention of patients, the FDA, and Congress to the possible health risks of medical devices. ${ }^{13}$ In response to these concerns, Congress passed the Medical Device Amendments (MDA) to the FDCA.14

The MDA sets out three categories of medical devices, and classifies them based on the risk they pose to the public. Class I devices are those which present no "unreasonable risk of illness or injury," and are subject only to general regulatory controls ${ }^{15}$ such as regulations pertaining to good manufacturing practices, labeling, and adverse experience reporting (discussed in greater detail below).16 Class I devices include hand held surgical instruments, latex gloves, and bandages. ${ }^{17}$ Class II devices present more risk than Class I, and as a consequence are subject to special controls which include the "promulgation of performance standards, postmarket surveillance, patient

11 Nancy W. Mathewson, History of Medical Device Regulation, in Medical Device Regulation \& Compliance 1, 1 (Stephen D. Terman \& Neil F. O'Flaherty eds., 2010), available at http://www.fdli.org/pdf/ pubs/FDLI-Medical-Device.pdf.

$12 \quad I d$.

13 Medtronic, Inc. v. Lohr, 518 U.S. 470, 475-76 (1996).

14 The Medical Device Amendments, 21 U.S.C. $\S 360 \mathrm{c}$ (2012).

1521 U.S.C. $\S 360 \mathrm{c}(\mathrm{a})(1)(\mathrm{A})(\mathrm{ii})(\mathrm{II})$ (2012).

16 Robert B. Leflar \& Robert S. Adler, The Preemption Pentad: Federal Preemption of Products Liability Claims After Medtronic, 64 TENN. L. REV. 691, 721 (1997).

17 Medical Devices: General and Special Controls, U.S. FOOD AND DRUG ADMIN., http://www.fda.gov/MedicalDevices/DeviceRegulationand Guidance/Overview/GeneralandSpecialControls/default.htm (last visited Nov. 25, 2012) [hereinafter General and Special Controls]. 
registries, development and dissemination of guidelines" and any other actions deemed appropriate by the Secretary of the Department of Health and Human Services. 18 Examples of Class II devices include surgical drapes, powered wheel chairs, ${ }^{19}$ and tampons. ${ }^{20}$ The last class of devices, Class III, are those that present the most risk to patients and are intended for use in supporting or sustaining life. ${ }^{21}$ Examples of Class III devices include pacemakers, ${ }^{22}$ orthopedic bone screws, ${ }^{23}$ and catheters. ${ }^{24}$

The FDA regulates the manufacture of all devices through what are known as Quality System Regulations, Current Good Manufacturing Process (GMP) requirements, postmarket surveillance, and adverse experience reporting. ${ }^{25}$ These regulations require the manufacturer of the device to establish and maintain procedures able to prevent contamination of the equipment and products by sub-stances that could have an adverse effect on device quality and safety. ${ }^{26}$ Additionally, each manufacturer must also implement processes to test the products for compliance with the product specifications (established and maintained by the manufacturer, subject to verification and/or validation by the FDA as appropriate to ensure device safety ${ }^{27}$ ), to identify and control nonconforming products, and to document such compliance before the products are sold or used. ${ }^{28}$ Class I and Class II devices, because they present little risk of illness or injury, are subject to only these general regulatory controls of safety and

\footnotetext{
1821 U.S.C. $\S 360 \mathrm{c}(\mathrm{a})(1)(\mathrm{B})(2012)$.

19 General and Special Controls, supra note 17.

20 Nat'l Bank of Commerce v. Kimberly-Clark Corp., 38 F.3d 988, 990 (8th Cir. 1994) (citing 21 C.F.R. $\$ \S 884.5460,884.5470$ (2012)).

2121 U.S.C. $\$ 360 \mathrm{c}(\mathrm{a})(1)(\mathrm{C})(2012)$.

22 General and Special Controls, supra note 17.

Buckman Co. v. Plaintiff's Legal Comm., 531 U.S. 341, 344

24 Riegel v. Medtronic, Inc., 552 U.S. 312, 320 (2008).

25 General and Special Controls, supra note 17.

2621 C.F.R. $\S 820.70(\mathrm{e})(2012)$.

2721 C.F.R. $\S 820.70$ (b) (2012).

2821 C.F.R. $\$ \S 820.72-820.90$ (2012).
} (2001). 
effectiveness. $^{29}$ Consequently, there are no federal regulations of design or manufacture for Class I or II devices. ${ }^{30}$

Class III devices are treated quite differently, however, and require extensive evaluation and approval of their safety and efficacy, while also being subject to the same general regulatory controls. The MDA provided that all post amendment devices were to be automatically classified as Class III, unless they met a specific exception. ${ }^{31}$ Class III devices are required to undergo a process of scientific review to ensure their safety and effectiveness before they are permitted to be marketed, known as premarket approval (PMA). ${ }^{32}$ The application for PMA is lengthy, and manufacturers must submit detailed information regarding the safety and efficacy of their devices. Specifically, the FDA requires that the applicant document descriptions, investigations, and other relevant information pertaining to the safety and efficacy of the device for which approval is sought. ${ }^{33}$ The application must include a full description of the device, its components, how it works, and its indications for use, as well as the methods used in the manufacture, processing, packaging, and installation of the device. ${ }^{34}$ Additionally, information regarding the proposed labeling, investigations, and directions for use must also be included. ${ }^{35}$ A PMA, if granted, will be based on

2921 U.S.C. $\$ 360 \mathrm{c}(\mathrm{a})(1)(\mathrm{A})(\mathrm{ii})(\mathrm{II})(2012)$.

30 As a general matter, the FDA does have the authority to impose specific regulations pertaining to manufacture or labeling, instruction or warning if it determines the safe use of a Class I or II device requires it. See Section $\operatorname{II}(\mathrm{B})(1)$ below for a discussion on these regulations. See also, e.g., 21 C.F.R. $§ 801.430$ (2012) (warning requirements for tampons).

31 IOM REPORT, supra note 6, at 86. Devices were not classified as Class III if they were on the market prior to the enactment of the MDA or were substantially equivalent to devices on the market at that time, 21 U.S.C. $\S 360 \mathrm{c}(\mathrm{f})(1)$ (2012), or the manufacturer of the device may petition for a reclassification of the device to Class I or II. 21 U.S.C. $\S$ $360 \mathrm{c}(\mathrm{f})(3)(2012)$.

$32 \quad 21$ U.S.C. $\S 360 \mathrm{e}(2012)$.

$33 \quad 21$ U.S.C. $\$ 360$ e(c) (2012); 21 C.F.R. $\$ 814.20$ (2012).

$34 \quad 21$ U.S.C. $\$ 360 \mathrm{e}(\mathrm{c})(1)(2012)$.

$35 \quad 21$ U.S.C. $\S 360 \mathrm{e}(\mathrm{c})(2)(\mathrm{A})(2012)$. 
considerations of all of this information, and may specify requirements the device must meet (based on the information provided, as relevant) to be marketed. ${ }^{36}$ The Safe Medical Devices Act of 1990 gave the FDA the authority to issue regulations which require pre-production design controls for medical devices, in order ensure the safety and efficacy of the device. ${ }^{37}$ A Class III device that fails to meet the requirements specified in the PMA will be considered adulterated under the FDCA and cannot be marketed. ${ }^{38}$

Perhaps most importantly, the PMA application must include a summary of both the nonclinical laboratory studies and the clinical studies involving human subjects, as well as the conclusions drawn from these studies regarding the safety and efficacy of the device. ${ }^{39}$ The application also requires a clinical investigations section in which study protocols, safety and effectiveness data, adverse reactions, complications, device failures, patient information and complaints, and other clinical investigation information are disclosed. ${ }^{40}$ It is essential that the demonstrations of safety and effectiveness of the device are founded on good science and good scientific writing; if such information is lacking, the FDA will refuse to file the PMA application. ${ }^{41}$ FDA regulations provide 180 days to review the PMA and make a determination. ${ }^{42}$ In practice, however,

36 Medical Devices: Premarket Approvals, U.S. FOOD AND DRUG ADMIN., http://www.fda.gov/MedicalDevices/ProductsandMedical Procedures/DeviceApprovalsandClearances/PMAApprovals/default.htm (last visited Nov. 26, 2012).

37 Center for Devices and Radiological Health, Alternate APPROACHES TO DEMONSTRATING Substantial EqUIVAlENCE IN PREMARKET NOTIFICATIONS: FINAL GUIDANCE 3 (1998), available at http://www.fda.gov/downloads/MedicalDevices/DeviceRegulationand Guidance/GuidanceDocuments/ucm080189.pdf.

$38 \quad I d$.

$39 \quad 21$ C.F.R. $\S 814.20(\mathrm{~b})(3)$ (v)-(vi) (2012).

$40 \quad 21$ C.F.R. $\$ 814.20(\mathrm{~b})(6)$ (2012).

41 Medical Devices: Premarket Approval (PMA), U.S. FooD AND DRUG ADMIN., http://www.fda.gov/medicaldevices/deviceregulationand guidance/howtomarketyourdevice/premarketsubmissions/premarketapp rovalpma/default.htm (last visited Nov. 26, 2012) [hereinafter PMA].

$42 \quad 21$ C.F.R. $\$ 814.40$ (2012). 
the review time is normally longer. ${ }^{43}$ It has been reported that the FDA spends "an average of 1,200 hours on each submission."44 Although this review is detailed, there is some debate as to the effectiveness of this review process. ${ }^{45}$

To avoid this lengthy PMA process, manufacturers can generally attempt to bring their device to market through one of three exemptions. The first, the Investigational Device Exemption (IDE), ${ }^{46}$ is available to manufacturers who want to test an experimental device on humans, or who want to test an already available device for use for a new indication. ${ }^{47}$ The manufacturer must obtain permission for these tests from both the FDA and from the institutional review board (IRB) of the institution at which the testing will be performed. ${ }^{48}$ To obtain an IDE, the applicant must submit to the FDA information about the device and how the experiment will be conducted. ${ }^{49}$ It is primarily upon this submission that the FDA makes its decision, and approval does not involve a finding by the agency that the manufacturer has made correct decisions about the design, labeling, or production of the device under investigation. ${ }^{50}$

$43 \quad P M A$, supra note 41.

44 Medtronic, Inc. v. Lohr, 518 U.S. 470, 477 (1996).

45 See, e.g., David Brennan, Federal Preemption of All State Law Tort Claims in Riegel v. Medtronic: $A$ Need to Undo a Serious Wrong, 36 W. ST. U. L. REV. 137, 161-64 (2009) ("POGO [Project on Government Oversight] observed that the effect of the Riegel decision by the U.S. Supreme Court was to nearly 'condone the notion' - challenged repeatedly .. . - that the 'FDA 'spends an average of 1,200 hours reviewing each application ... and [it only] grants premarket approval only [where] it finds [that] there is a 'reasonable assurance' of the device's 'safety and effectiveness." Independent of POGO and the FDA's suggestions of a rigorous and robust application of the MDA to its processes to prevent inadequately reviewed medical devices from entering the market place, there is credible and sufficient information . . . coming from the FDA's own scientists, Congressional lead-ers, nongovernmental organizations ... and the General Accountability Office . . . to demonstrate substantial doubt as to the overall effectiveness of the Agency in the sphere of Class III medical devices.").

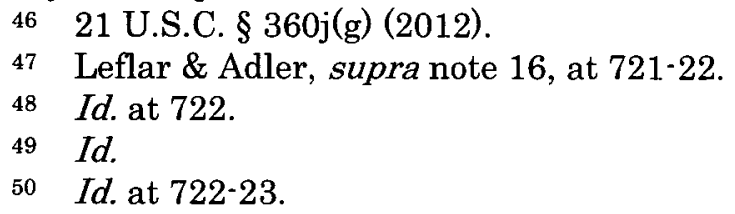


IDE devices are used under the supervision of the FDA during the trial process and after, and the FDA is able to then impose requirements on the device regarding design, manufacture, and safety. ${ }^{51}$ The requirements of the PMA will be satisfied and the device will receive PMA for broader use if the IDE trials are able to prove the device is satisfactorily safe and effective. ${ }^{52}$

A Humanitarian Device Exemption (HDE) is also available to exempt from the premarket approval process devices that are intended to benefit only very small patient populations through treatment in near-death situations. ${ }^{53}$ This exemption can be used in situations where the required approval by an IRB cannot be obtained in time to prevent serious harm or death to a patient. ${ }^{54}$ The FDA guidelines permit the use of the device in these circumstances for purely humanitarian purposes, and this permission is not intended to equate with a PMA approval of the safety or efficacy of the device. ${ }^{55}$ Neither the IDE nor the HDE exemptions will be addressed further in this article.

A vast majority of devices are exempt from the PMA approval process through something known as $\S 510(\mathrm{k})$ premarket notification. ${ }^{56}$ The MDA grandfathered in any devices that were legally on the market before May 28, $1976^{57}$ and also permitted devices that were shown to be "substantially equivalent" to these pre-1976 devices ${ }^{58}$ to avoid the PMA process through premarket notification. The manufacturer or sponsor of the device must receive an order from the FDA finding the device to be substantially

51 Burgos v. Satiety, Inc., No. 10-CV-2680 (JG), 2010 WL 4907764 , at ${ }^{*} 2$ (E.D.N.Y. Nov. 30, 2010).

52 Id. (citing In re Orthopedic Bone Screw Prods. Liab. Litig., 193 F.3d 781, 786 (3d Cir.1999)).

53 Brennan, supra note 45 , at 144 .

54 Id.

$55 \quad I d$.

56 Jeffrey Zigler et al., Medical Device Reporting: Issues with Class III Medical Devices, 62 FooD \& DRUG L.J. 573, 573 (2007); see also Medtronic, Inc. v. Lohr, 518 U.S. 470, 479 (1996).

$57 \quad 21$ U.S.C. $\S 360 \mathrm{e}(\mathrm{b})(1)(\mathrm{A})(2012)$.

$58 \quad 21$ U.S.C. $\S 360 \mathrm{e}(\mathrm{b})(1)(B)(2012)$. 
equivalent to a predicate device. ${ }^{59}$ This order clears the device for commercial distribution in the U.S. ${ }^{60}$ This $510(\mathrm{k})$ process was initially created as a way to keep the valuable medical device products consumers had used for years available on the market, and to prevent unfair monopolization of the marketplace by those manufacturers fortunate enough to get their products out before the enactment of the MDA. However, the review process has taken a very different form today. Only conceptually new devices marketed since 1976 have been required to undergo rigorous scientific demonstration of safety and efficacy. ${ }^{61}$ Section $510(\mathrm{k})$ review requires the submission of comparably little information on the device, and the review is usually completed by the FDA in twenty hours. ${ }^{62}$

The concept of substantial equivalence is central to the $510(\mathrm{k})$ clearance process. When the premarket notification was first created, the FDA intended to ensure new devices cleared for marketing through this process did not differ from their predicate devices in a way that had an effect on

59 A predicate device is "a legally marketed device ... that is not subject to Premarket Approval (PMA).” FDA, How to Find a Predicate Device, http://www.fda.gov/MedicalDevices/DeviceRegulationand Guidance/HowtoMarketYourDevice/PremarketSubmissions/Premarket Notification $510 \mathrm{k} / \mathrm{ucm} 134571 . \mathrm{htm}$.

60 Medical Devices: Premarket Notification (501(k)), U.S. FOOD AND DRUG ADMIN., http://www.fda.gov/medicaldevices/deviceregulation andguidance/howtomarketyourdevice/premarketsubmissions/premarket notification $510 \mathrm{k} /$ default.htm (last visited Nov. 26, 2012).

61 Zigler, supra note 56, at 573. In 2007, the Government Accountability Office (GAO) began a study to determine which review process, 510(k) or PMA, was used by the FDA to review different types of device submissions. U.S. GOV'T ACCOUNTABILITY OFFICE, GAO-09-190, Medical Devices: FDA Should TaKe Steps To Ensure That High' RISK Device TyPes ARE APPROved THROUGH THE Most STRINGENT PRemarket REVIEW PRocess 4 (2009). The GAO found that, from 2003 to 2007, the FDA reviewed 13,199 submissions for class I and II devices through the $510(\mathrm{k})$ process and cleared 90 percent. Id. at 6 . The FDA also reviewed $342510(\mathrm{k})$ submissions for class III devices, and cleared 67 percent of these. Id. In contrast, 217 original and 784 supplemental submissions for class III devices were reviewed through the PMA process, and 78 and 85 percent, respectively, of these sub-missions were approved. Id.

62 Medtronic, Inc. v. Lohr, 518 U.S. 470, 479 (1996). 
the safety or efficacy of the device. In a guidance issued by the FDA, the concept was described as follows:

The term "substantially equivalent" is not intended to be so narrow as to refer only to devices that are identical to marketed devices nor so broad as to refer to devices which are intended to be used for the same purposes as marketed products. The committee believes that the term should be construed narrowly where necessary to assure the safety and effectiveness of a device but not narrowly where differences between a new device and a marketed device do not relate to safety and effectiveness. Thus, differences between "new" and marketed devices in materials, design, or energy source, for example, would have a $\mathrm{b}[\mathrm{e}]$ aring on the adequacy of information as to a new device's safety and effectiveness, and such devices should be automatically classified into class III. On the other hand, copies of devices marketed prior to enactment, or devices whose variations are immaterial to safety and effectiveness would not necessarily fall under the automatic classification scheme. ${ }^{63}$

As codified in the U.S. Code, substantial equivalence means that either the device has the same technological characteristics ${ }^{64}$ as the predicate device, or the device has

63 Guidance on the CDRH Premarket Notification Review Program, U.S. Food and Drug Admin., http://www.fda.gov/ MedicalDevices/DeviceRegulationandGuidance/GuidanceDocuments/ ucm081383.htm (last visited Nov. 25, 2012) (quoting H.R. Rep. No. 94853 , at $36-37(1976)$ ).

$64 \quad 21$ U.S.C. $\$ 360 \mathrm{c}(\mathrm{i})(1)(\mathrm{B}) \quad$ (2012) ("[T]he term 'different technological characteristics' means, with respect to a device being compared to a predicate device, that there is a significant change in the materials, design, energy source, or other features of the device from those of the predicate device."). 
different technological characteristics but sufficient clinical data is provided to demonstrate it is as safe and effective as the predicate device. ${ }^{65}$ The device also cannot raise different questions of safety and effectiveness than those raised by the predicate device. ${ }^{66}$ The concept of substantial equivalence can be read fairly broadly, particularly since the devices can be compared to a pre-1976 device or any device previously cleared through the $510(\mathrm{k})$ process. ${ }^{67} \mathrm{In}$ effect, devices may be cleared for marketing because of a finding that they are as safe and effective as devices no longer in use. ${ }^{68}$ However, a device previously removed from the market by the FDA or by a judicial order finding the device misbranded or adulterated may not be used as the predicate device in a determination of substantial equivalence..$^{69}$

\section{B. FDA Regulation}

\section{Rulemaking and Guidance}

One important way the FDA increases the medical device industry's compliance with its regulations is through the issuance of rules and guidelines to clarify expectations. As industry participants become better informed and develop a greater understanding of their obligations, their ability to comply with them is improved; consequently, the need for enforcement of the regulations decreases. The Administrative Procedure Act (APA) was enacted in 1946 to regulate and standard-ize agency actions and the

$65 \quad 21$ U.S.C. $\S 360 \mathrm{c}(\mathrm{i})(1)(\mathrm{A})(2012)$.

66 Office of Device Evaluation, SMda Changes: Premarket NOTIFICATION; REGULATORY REQUIREMENTS FOR MEDICAL DEVICES (510K) MANUAL INSERT (1992), available at http://www.fda.gov/ downloads/MedicalDevices/DeviceRegulationandGuidance/GuidanceDoc uments/UCM081355.pdf.

67 How Safe Are Medical Devices?, N.Y. Times, Aug. 4, 2011, http://www.nytimes.com/2011/08/05/opinion/how-safe-are-medicaldevices.html?_r=1 (last visited Nov. 26, 2012).

68 Id.

6921 U.S.C. $\S 360 \mathrm{c}(\mathrm{i})(2)(2012)$. 
rulemaking process. ${ }^{70}$ Rulemaking refers to the process by which administrative agencies, in following broad policy mandates enacted by the legislature through the passage of statutes, create regulations. Regulations refer to rules and/or orders issued by an agency which have the force of law; that is, which compel action by imposing a legal requirement through the allocation of responsibilities or constraint of rights. ${ }^{71}$

The APA recognizes only three forms of rulemaking: formal (trial-like hearing), informal (notice and comment), and negotiated. ${ }^{72}$ Informal rulemaking is by far the most common, and affords the public notice of the proposed rule and the opportunity to respond and comment before it is enacted. ${ }^{73}$ Formal rulemaking is used by agencies only when a statute requires it, and the formal adjudication procedures laid out in the APA, which involve the submission of evidence and the opportunity for crossexamination, must be followed. ${ }^{74}$ The FDCA requires the FDA to follow formal rulemaking procedures before issuing a rule. ${ }^{75}$ Although in theory these formal procedures may provide the best way to ensure affected parties are afforded due process in the FDA's rulemaking process, the reality is that these formal procedures are incredibly time consuming and inefficient. ${ }^{76}$ Consequently courts very rarely compel agencies to employ these formal measures, instead holding that the submission of written comments by interested parties satisfied the APA's requirements for a proper hearing. ${ }^{77}$

70 Kenneth F. Warren, Administrative LaW IN THE Political SYSTEM 215 (2004).

71 Rulemaking, BLACK's LAW DICTIONARY (9th ed. 2009).

72 WARREN, supra note 70 , at 218.

73 Id.

74 Id.

75 Id. at $219-20$.

76 Id. at 220 ("One hearing, which focused on whether peanut butter should contain 87.5 percent or 90 percent peanuts, produced a weighty 7,736-page transcript and lasted about nine years.").

77 Id.; United States v. Florida E. Coast Ry. Co., 410 U.S. 224, 24041 (1973) ("[W]e are convinced that the term 'hearing' as used [in the APA] does not necessarily embrace either the right to present evidence 
The FDCA included in its section 701(a) a general rulemaking grant for the FDA to issue guidance, but this grant did not confer overarching legislative rulemaking authority. ${ }^{78}$ Section 701 set forth detailed procedures for public hearings and judicial review to be followed in the promulgation of rules (formal rulemaking procedures), and section 701(a) granted a general rulemaking power to promulgate rules in the enforcement of the FDCA. ${ }^{79}$ Rules promulgated under the authority granted under section 701(a), however, were not granted the force of law because a violator of any regulations promulgated thereunder would not be subject to any sanctions, penalties, or other legal consequences. ${ }^{80}$

In contrast, there were several specific rulemaking grants throughout the FDCA which authorized rulemaking with the force of law over specific issues; for example, misbranding and the use of marks, stamps, tags, or labels in foods. ${ }^{81}$ These regulations were given legislative effect by sections of the FDCA which expressly made their violation unlawful and subject to penalties. ${ }^{82}$ In the 1960 s and 70 s the FDA began to assert a right to issue legislative rules using informal notice-and-comment procedures. ${ }^{83}$ To do this, the FDA's chief counsel Peter Barton Hutt asserted that the FDCA should be viewed as laying out a set of fundamental objectives for the agency and the broad authority to implement these objectives through a power to do anything not specifically made an exception or withheld by the FDCA. ${ }^{84}$

orally and to cross-examine opposing witnesses, or the right to present oral argument to the agency's decisionmaker .... [T] [he [APA] makes it plain that a specific statutory mandate that the proceedings take place on the record after hearing may be satisfied in some circumstances by evidentiary submission in written form only.").

78 Thomas W. Merrill \& Kathryn Tongue Watts, Agency Rules with the Force of Law: The Original Convention, 116 HARV. L. REV. 467, 557 (2002).

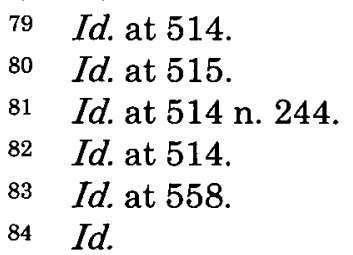


This theory eventually made it to the Supreme Court when regulations issued by the FDA under 701(a) authority were challenged. 85 The Court assumed without discussion that the FDA indeed had the authority to issue the regulations. ${ }^{86}$ Later, the Second Circuit in National Nutritional Foods Association v. Weinberger expressly held the FDA has such general rulemaking authority. The court explained:

Congress' establishment of a specific (and elaborate) procedure in [\$] 701(e) authorizing the FDA to promulgate regulations in certain fields was in addition to and not in derogation of the general rule-making power granted to the FDA by $\S 701(\mathrm{a})$. Under the latter section, furthermore, the FDA may follow streamlined procedures designed to avoid the endless delays that have tended to paralyze adjudicatory hearings and render them ineffective as a means of utilizing agency expertise. ${ }^{87}$

Although recognized by the courts as an efficient way for the FDA to avoid the cumbersome hearings required of formal rulemaking in the exercise of its authority, informal rulemaking does present problems of its own for the FDA. All branches of government have imposed additional procedural demands on the informal process, making it increasingly more difficult to issue rules in this way. ${ }^{88} \mathrm{In}$ response, the FDA has shifted toward the promulgation of nonbinding guidelines, which are quicker and easier to

85 See USV Pharm. Corp. v. Weinberger, 412 U.S. 655 (1973); Weinberger v. Bentex Pharm., Inc., 412 U.S. 645 (1973); Ciba Corp. v. Weinberger, 412 U.S. 640 (1973); Weinberger v. Hynson, Westcott \& Dunning, Inc., 412 U.S. 609 (1973).

86 Merrill \& Watts, supra note 78, at 559.

87 Nat'l Nutritional Foods Ass'n v. Weinberger, 512 F.2d 688, 69798 (2d Cir. 1975).

88 Lars Noah, The Little Agency That Could (Act with Indifference to Constitutional and Statutory Strictures), 93 CORNELL L. REV. 901, 904 (2008). 
issue. One example of this is the FDA's decision to, rather than amend its (at that time) twenty-five year old regulations defining and outlining "current" good manufacturing practices for drugs, instead issue guidance for the adoption of new and modern quality control technologies by the pharmaceutical industry. ${ }^{89}$ This growing dependence on nonbinding guidelines presents its own problems for the agency, however. Not only can these rules escape the normal procedural safeguards set in place for rulemaking, but they also allow the FDA to take a stance without establishing a definitive position, leaving the regulated entities guessing about their own obligations and rights under the guidance. ${ }^{90}$ Congress has recognized the importance of the ease and efficiency these guidance documents offer administrative agencies, and Congress even endorsed a greater reliance on guidance documents issued by agencies. ${ }^{91}$

In the regulation of medical devices, the FDA can issue rules or guidance pertaining to any aspects of the device that fall within the scope of the FDCA which, due to the ability of medical devices to present a risk of injury, can be quite extensive depending on the device. For the purposes of the rest of this paper, "rule" refers to a regulation that has the force of law; one that subjects a violator to sanctions, penalties, or other legal consequences. ${ }^{92}$ Some examples of rulemaking include the general regulatory controls of safety and effectiveness ${ }^{93}$ such as regulations pertaining to GMP and labeling, postmarket surveillance, and adverse experience reporting (discussed in greater detail below).94 For certain higher-risk devices, regulations pertaining to

89 Id. at 904-5; Leila Abboud \& Scott Hensley, Factory Shift: New Prescription For Drug Makers: Update the Plants; After Years of Neglect, Industry Focuses on Manufacturing; FDA Acts as a Catalyst; The Three-Story Blender, WALL ST. J., Sept. 3, 2003, at A1.

90 Noah, supra note 88 , at 905 .

91 Id.

92 See generally Merril \& Watts, supra note 78 , at $515-16$ (discussing legislative history granting rulemaking power to Secretary of the FDA).

$93 \quad 21$ U.S.C. $\$ 360 c(a)(1)(\mathrm{A})(\mathrm{ii})(\mathrm{II})$ (2012).

94 General and Special Controls, supra note 17. 
specific aspects of the design or manufacture of the devices may also be available. There have been times when the FDA has issued regulations for specific devices which impose particular labeling or warning requirements. ${ }^{95}$ An ex-ample of this is the FDA's requirement ${ }^{96}$ that tampons include labeling that warns customers of the dangers of Toxic Shock Syndrome and how it can be avoided. ${ }^{97}$ Such requirements will not be uniformly applied to all classes of devices or all devices within a class, but may be imposed on specific devices or types of devices.

In contrast, "guidance" refers to documents that are prepared for FDA staff, applicants or sponsors of devices, and the general public that describe the FDA's policy on or interpretation of a regulatory issue. ${ }^{98}$ Guidance documents can relate to the "design, production, labeling, promotion, manufacturing, and testing of regulated products; the processing, content, and evaluation or approval of submissions; and inspection and enforcement policies."99 Guidance documents are helpful and persuasive, and can make the application and clearance process more efficient when followed, but do not have the same effect as regulations and do not amount to actual legal requirements.

\section{Reporting and Postmarket Surveillance}

Due to the fact that devices brought to market through the $510(\mathrm{k})$ clearance process avoided any kind of premarket review, a strong postmarket surveillance system is

95 See 21 C.F.R. $\$ 801.437$ (2012) ( providing labeling requirements for allergy warning on latex gloves); CENTER FOR DEVICES AND RADIOLOGICAL HEALTH, GUIDANCE FOR INDUSTRY AND FOOD AND DRUG Administration StafF: CONTACT LENS CARE Products Labeling (2010), available at http:// www.fda.gov/downloads/MedicalDevices/ DeviceRegulationandGuidance/GuidanceDocuments/UCM223665.pdf (providing guidance on labeling and package insert requirements for contact lens solution).

96 21 C.F.R. $\$ 801.430$ (2012).

97 Nat'l Bank of Commerce v. Kimberly-Clark Corp., 38 F.3d 988, 990 (8th Cir. 1994).

$98 \quad 21$ C.F.R. $\$ 10.115(2012)$.

99

Id. 
important to ensure the safety of medical devices. Postmarket surveillance includes a variety of programs, including medical device reporting (MDR) by manufacturers and user facilities as well as third-party safety monitoring. ${ }^{100}$ Reporting includes adverse-event reporting of incidents resulting in serious injury or death, and malfunction reporting after a device fails without causing an adverse event. ${ }^{101}$ Most of this reporting is done by manufacturers, although the Safe Medical Devices Amendments of 1990 requires healthcare facilities to report device-related death or serious injuries to the manufacturer. ${ }^{102}$ Generally, patients, healthcare professionals, and caregivers have no legal obligation to report adverse medical events; however, they can provide voluntary reports through the FDA's MedWatch program. ${ }^{103}$

There are barriers to the effectiveness of these programs, however. One of the fundamental steps of MDR is, after recognizing that an adverse event has occurred, linking that event with one or more possible devices as causal or contributing factors. ${ }^{104}$ It can be difficult for practitioners to assess the role of the device in the patient's unique medical problem, since those with the relevant expertise may not be available to assist or take action at the time the patient presents for corrective action. ${ }^{105}$ For example, it may be easy for physicians to notice unexpected harms resulting from the use of a device, but they are less likely to detect an increased probability of familiar injuries that may result from the device. ${ }^{106}$ Furthermore, be-cause the onset of

100 IOM REPORT, supra note 6 , at 123.

101 Id.

102 Id. at $124-25$.

103 See Id. at 124; Safety: Reporting by Consumers, U.S. FooD AND DRUG ADMIN., http://www.fda.gov/Safety/MedWatch/HowToReport/ ucm053074.htm (last visited Nov. 26, 2012) (MedWatch is the FDA's voluntary reporting program for the reporting of serious reactions, product quality problems, therapeutic inequivalence/failure, and product use errors which result from the use of any human medical products, including medical devices.).

104 Id. at 125.

105 Id.

106 Catherine T. Struve, The FDA and the Tort System: Postmarketing Surveillance, Compensation, and the Role of Litigation, 
medical problems may be delayed, patients suffering the effects of problematic devices may no longer be patients of the facility which used the device in the patient's care, the facility with an obligation to report adverse events. ${ }^{107}$ In contrast, the problems arising from the voluntary reporting through the MedWatch program may result from over reporting. "The MedWatch system generates some 22,000 reports each year, and of these a substantial number may not involve a causal link between the product and the injury."108

Follow-up inquiries and investigations performed by the manufacturers are important components of the postmarket surveillance process. The follow-up inquires, which are required by the FDA for the majority of reports received, enable the manufacturer to fill in the gaps in the information initially reported 109 and en-able a better evaluation and assessment of the device and the event. Investigations work to further improve the information in the MDR by filling in information gaps that may exist. However, investigations may be impeded by the patient, treating physician, or facility refusals to provide additional information. ${ }^{110}$ Additionally, because physicians and healthcare facilities are not reimbursed for the time it takes to respond to requests for additional information, the efficacy of such follow-up may be impeded.111

Once the manufacturer has obtained all the information about the event, it must then review the record in a timely fashion and determine whether the event meets the threshold for a reportable event.112 Manufacturers have thirty days to report if a device may have caused or contributed to a death or serious injury, or if death or

2 Yale J. HEALTh POL'Y, L. \& ETHICS 587, 603 (2005). For example, it may not be easy for healthcare professionals to determine whether a device may cause or increase the severity of a condition that is relatively common to the control population considered. Id. at n.74.

107 IOM REPORT, supra note 6, at 126.

108 Struve, supra note 106 , at 604.

109 IOM REPORT, supra note 6, at 126.

$110 I d$.

111 Id.

112 Id. 
serious injury could result if the malfunction reoccurs. ${ }^{113}$ If the reportable event requires remedial action to prevent a substantial risk of harm to public health, the manufacturer must report within five days. ${ }^{114}$ One study found that, in $2007,31 \%$ of the critical five-day reports were submitted late and $39 \%$ of the death and injury adverse-event reports were late.115 "The inadequacy of the current postmarketing surveillance system and the resulting lack of data make it impossible to confidently draw broad conclusions about the safety and effectiveness of products that are on the market.". 116

Each MDR is entered into an FDA event database and screened by a safety analyst, "generally a nurse or engineer working for the FDA," to identify a signal of risk for the potential harm. ${ }^{117}$ This task is not easily accomplished, due in part to the limited experience of the reviewer with the new device, a lack of input by the FDA's premarket staff (who have gained some familiarity with the device as a result of the premarket notification process), and the large number of reports each individual analyst must address. ${ }^{118}$ Efforts to reduce the workload of the safety analysts and to open communication between premarket staff and report screening staff have been thwarted by logistical problems arising from the FDA's limited resources, the differing physical locations of the staff, and the heavy workload of all FDA employees. ${ }^{119}$ When signals are found, they are entered into the $\mathrm{CDRH}$ database, which includes information about medical device malfunctions as well as foreign inspections and labeling and software issues. ${ }^{120}$ The

$\begin{array}{ll}113 & I d . \text { at } 127 . \\ 114 & I d . \\ 115 & I d . \\ 116 & I d . \text { at } 129 . \\ 117 & I d . \text { at } 127 . \\ 118 & I d . \\ 119 & I d . \text { at } 127-28 . \\ 120 & C D R H\end{array}$

http://www.fda.gov/AboutFDA/CentersOffices/OfficeofMedicalProducts andTobacco/CDRH/CDRHTransparency/ucm223770.htm (last visited Nov. 27, 2012). This database contains only information from inspections which were the CDRH's respon-sibility, about $25 \%$ of the total device inspections, and have been conducted since 2008. 
primary repository for adverse event reports remains the Manufacturer and User Facility Device Experience database, which is specific to medical device malfunctions and adverse events. ${ }^{121}$ However, this database is difficult to use because it does not incorporate relevant information from other FDA databases, such as the CDRH database, and many of the entries are incomplete or misclassified. ${ }^{122}$ The different databases were created at different times to serve different purposes, and although they share information relevant to each other, the databases have not yet been incorporated into a single information source.

In addition to reporting, the FDA conducts postmarket surveillance of devices through a number of other mechanisms. The FDA can issue orders requiring manufacturers to track certain types of devices through the distribution chain. ${ }^{123}$ This is done to ensure that manufacturers are able to promptly locate the devices in commercial distribution which, in the event serious health risks are presented by the devices, will facilitate notifications and recalls the FDA may order. ${ }^{124}$ Manufacturers are expected to have the ability to promptly provide information about the location of devices already distributed to patients and the devices in the manufacturer's or distributor's inventory. ${ }^{125}$ To improve the FDA's tracking efforts, the FDA Amendments Act called for the FDA to develop a unique device identification (UDI)

121 IOM Report, supra note 6, at 128; see also Manufacturer and User Facility Device Experience Database - (MAUDE), FDA.gov, http://www.fda.gov/MedicalDevices/DeviceRegulationandGuidance/ PostmarketRequirements/ReportingAdverseEvents/ucm127891.htm (last visited Nov. 27, 2012) ("MAUDE data represents reports of adverse events involving medical devices. The data consists of voluntary reports since June 1993, user facility reports since 1991, distributor reports since 1993, and manufacturer reports since August 1996.").

122 IOM REPORT, supra note 6, at 128.

123 Medical Device Tracking, FDA.Gov, http://www.fda.gov/Medical Devices/DeviceRegulationandGuidance/PostmarketRequirements/ MedicalDeviceTracking/default.htm (last visited Nov. 27, 2012).

124 Id.

125 IOM REPORT, supra note 6, at 129 (noting that information about distributed devices is expected be provided within ten days, and information about devices in inventory within three days). 
system. ${ }^{126}$ Although pilot activities have been conducted, this has not yet been implemented. ${ }^{127}$ Manufacturers express concern about the alignment of the FDA's UDI standards with those of other regulatory systems and their ability to simultaneously comply with both. ${ }^{128}$

The FDA has also established a postmarket risk identification and analysis system known as the Sentinel Initiative to enable the active monitoring of the safety of all FDA regulated products. ${ }^{129}$ Prior to this initiative, the FDA had generally worked with healthcare systems individually to evaluate a particular product's safety issues, although it also made use of administrative and insurance claims databases in investigating safety of products. ${ }^{130}$ The Sentinel Initiative aims to create a linked, sustainable system that will draw upon the electronic healthcare data of many sources to enable continuous active monitoring of product safety. ${ }^{131}$ The initiative is still in its early phases of system planning and design, but a pilot "Mini-Sentinel" project has been developed. ${ }^{132}$ This project analyzed administrative claims data and de-identified electronic health record data with the hopes of uncovering information about medical device exposures and outcomes. ${ }^{133}$ While this

126 Food and Drug Administration Amendments Act of 2007, P.L. $110-85, \S 226,121$ Stat. 823,854 (codified as amended at 21 U.S.C. $360 \mathrm{i}$ (2007)).

127 IOM REPORT, supra note 6, at 133.

128 Id.

129 FDA's Sentinel Initiative - Background, FDA.Gov, http://www.fda.gov/Safety/FDAsSentinel Initiative/ucm149340.htm (last visited Dec. 21, 2012) [hereinafter Sentinel Initiative]; see also Food and Drug Administration Amendments Act of 2007, P.L. 110-85, $\S 905(\mathrm{a})$, 121 Stat. 823, 944 (codified as amended at 21 U.S.C. $\S 355$ (2007)) (noting that the Sentinel Initiative was to establish and maintain procedures for "risk identification and analysis ... of data on all serious adverse drug experiences"); but see IOM REPORT, supra note 6, at 131 (noting that the FDA, through its general authority under FDCA section $1003(b)(2)(c)$ has broadened the scope of the Sentinel system to include medical devices).

130 Sentinel Initiative, supra note129.

131 Id.

132 IOM REPORT, supra note 6 , at 131.

133 Id.; see also Background History, MiNI-SENTINEL.ORG, http:// mini-sentinel.org/about_us/ (last visited Nov. 27, 2012). 
initiative will greatly facilitate the monitoring of FDA regulated products, its ability to improve the monitoring of $510(\mathrm{k})$ cleared devices is limited. Information about many issues, such as software problems, manufacturing defects, packaging and labeling errors, and errors resulting from device design, will not be gathered, leaving many potential safety consequences of $510(\mathrm{k})$ devices beyond the scope of the initiative's active monitoring. ${ }^{134}$ The database created by the Mini-Sentinel program can be used to make assessments describing "exposures to medical products, occurrences of particular diagnoses and medical procedures, health outcomes among individuals exposed to medical products, [and the] impact of FDA's regulatory actions and interventions." 135

Another pilot program, known as the Medical Product Surveillance Network (MedSun), was implemented in an effort to improve the reporting of adverse events and near misses through the involvement of trained risk managers at various health facilities. ${ }^{136}$ The hope is that the involvement of clinical professionals could improve not only the number of events reported, but also the quality of the information reported, ${ }^{137}$ through the program's creation of a two-way communication pathway between the FDA and the clinical site of care. ${ }^{138}$ The information obtained could be analyzed to uncover how devices are used and how errors occur, to prevent injuries from reoccurring in future uses of the devices, while also identify-ing trends that hopefully could identify developing problems and enable them to be addressed earlier, to prevent injuries from occurring at all. 139

134 IOM REPORT, supra note 6, at 132.

135 Types of Assessments, MiniSEnTINEL.ORG, http://minisentinel. org/product_evaluations/ default.aspx (last visited Nov. 27, 2012).

136 IOM REPORT, supra note 6, at 129.

137 Id.

138 SUSAN GARDNER \& MARILYN FLACK, DESIGNING A MEDICAL DEvice SURVEILlance NeTWORK: REPORT TO CONGRESS (1999) [hereinafter MEDSUN], available at http://www.fda.gov/MedicalDevices/ DeviceRegulationandGuidance/Overview/MedicalDeviceProvisionsofFDAMod ernizationAct/ucm168938.htm.

139 Id. at $\S 5.1$. 
Finally, section 522 of the FDCA grants the FDA the discretion to order any manufacturer to conduct post market surveillance on certain Class II or .Class III devices. ${ }^{140}$ Devices for which postmarket surveillance can be ordered include those whose failure is reasonably likely to have serious adverse health consequences, which are intended to be implanted in the body for more than one year or are life-sustaining or life-supporting devices used outside of a hospital facility, and devices which are expected to have significant use in pediatric populations. ${ }^{141}$ Manufacturers required to conduct this section 522 surveillance shall, upon receipt of the order, have thirty days to submit a plain for the required surveillance, which the Secretary of HHS must approve within sixty days. ${ }^{142}$ To be approved, the plan must effectively facilitate the collection of data useful in identifying previously unforeseen adverse events or other similarly helpful information. ${ }^{143}$ Generally, these studies focus on "one or two aspects of performance" of the device. ${ }^{144}$ The surveillance period may be ordered to last up to thirtysix months, and can be extended by mutual agreement between the manufacturer and the Secretary. ${ }^{145}$ This time frame is too short to enable the discovery, through these studies, of latent safety or effectiveness problems that might arise in the use of the device. ${ }^{146}$ Additionally, all critical information gleaned from the studies might not be required to be reported. ${ }^{147}$

140 Federal Food, Drug and Cosmetic Act, 21 U.S.C. $§ 360$ i(a) (2012).

141 Id.

142 Federal Food, Drug and Cosmetic Act, 21 U.S.C. $§ 360 \mathrm{i}(\mathrm{b})$ (2012).

143 Id.

144 IOM REPORT, supra note 6, at 132. (2012).

145 Federal Food, Drug and Cosmetic Act, 21 U.S.C. $\S 360 \mathrm{l}(\mathrm{b})$

146 IOM REPORT, supra note 6, at 132.

147 Id. 


\section{Enforcement Powers}

\section{a. Administrative}

While there are many regulations in place governing medical devices, their ability to protect patients will depend upon the extent to which the regulations can be enforced. When there is a problem with the safety or efficacy of a device, the FDA first seeks to work with the manufacturer to correct the problem voluntarily. In an effort to obtain voluntary compliance with a request the agency cannot directly impose on a manufacturer, the FDA may threaten to withhold a benefit or impose a sanction in an effort to encourage compliance. ${ }^{148}$ If the manufacturer is unwilling, the FDA has a number of legal remedies available to use in the enforcement of its regulations, including recalling the device, seizure of the device by federal marshals, or, for imported devices, detainment at the port of entry. ${ }^{149}$

When a regulation governing medical devices is violated, the first contact from the FDA is often a warning letter to the responsible individual or entity, instructing the recipient to take prompt action to correct the violation. ${ }^{150}$ "Warning letters are informal and advisory but are available to the public on the FDA's website."151 The effect of such a letter varies depending on the type of approval sought for the device. However, devices seeking 510(k) clearance generally cannot be blocked by a warn-ing letter unless there is a "substantial likelihood" of a serious risk of health from the device because of a specific GMP violation. ${ }^{152}$ In fiscal year 2011, the FDA's Center for Devices and Radiological Health issued 175 warning letters. ${ }^{153}$

148 Noah, supra note 88 , at 906.

149 IOM REPORT, supra note 6, at 133.

150 Id. at 134.

151 Id.

152 Id.

153 Warning Letters by FDA Center Fiscal Year 2011, FDA.GOV, http://www.fda.gov/downloads/ICECI/EnforcementActions/UCM285781. pdf. 
The FDA defines a recall as "the correction or removal of a device for human use where FDA finds that there is a reasonable probability that the device would cause serious, adverse health consequences or death."154 Recalls are usually voluntary, and are undertaken by manufacturers and distributers in an effort to carry out their responsibilities to protect the public from a risk of injury from their product(s) as an alternative to an FDA initiated seizure or other court action. ${ }^{155}$ Recalls include not only a request for the return of the product, but also any measures taken to correct any unsafe features of the device, such as software patches, placing stickers on packaging, revisions of labeling (adding warnings or clarifying instructions), informational letters, and servicing in the field. ${ }^{156}$ Additionally, manufacturers and importers are required to report to the FDA any voluntary corrections or removals they take to reduce a health risk posed by a device. ${ }^{157}$ The FDA classifies recalls "according to the degree of hazard" posed by the device. ${ }^{158}$ The most serious recalls, Class I, are reserved for situations where there is a "reasonable probability that use of or exposure to a violative product will cause serious adverse health consequences or death."159 Class II recalls are the most common, and are used when a product may cause temporary adverse effects, but in which there is a remote possibility of irreversible consequences. ${ }^{160}$ Class III recalls are used when the use of a product is not likely to cause adverse consequences, but for which there is enough likelihood to justify a recall. ${ }^{161}$

Although recalls can be helpful in providing information regarding signs of device safety, as well as the point in a

15421 C.F.R. $\$ 810.2(\mathrm{j})(2012)$.

15521 C.F.R. $\$ 7.40$ (2012).

156 IOM REPORT, supra note 6, at 134-35.

15721 C.F.R. $\$ 806.10$ (2012).

158 IOM REPORT, supra note 6, at 135 (noting that degree of hazard determinations are "based on injuries or deaths that have occurred, the likelihood of occurrence, the population exposed, and the immediate and long-term consequences").

$15921 \mathrm{CFR} \S 7.3(\mathrm{~m})(1)$.

$16021 \mathrm{CFR} \S 7.3(\mathrm{~m})(2)$.

$16121 \mathrm{CFR} \S 7.3(\mathrm{~m})(3)$. 
product's life cycle at which safety problems may begin to arise, improved postmarket surveillance will still be required to provide the full story of the safety of devices in clinical use. ${ }^{162}$ For example, it is easy to assume that all devices which have not been recalled by the FDA are safe and pose no potential safety problems; however, the possibility remains that some of these devices could have safety problems that have so far remained undetected. A study of $510(\mathrm{k})$ devices cleared between 1996 and 2009 revealed that 3,132 devices, or $6.47 \%$, were recalled between 2003 and 2009, and of those devices, $26.1 \%$ were recalled multiple times. ${ }^{163}$ Most of these recalls were due to errors in device manufacture or design, $28.8 \%$ and $28.4 \%$ respectively. ${ }^{164}$ Among the devices cleared after 2003, the vast majority, $91.5 \%$ remained free of recalls six years after clearance. ${ }^{165}$ In 2011, the FDA's Center for Devices and Radiological Health recalled 3,211 devices. ${ }^{166}$

The FDA has many enforcement options available to it, and consequently many mechanisms by which to ensure compliance with its regulations, but it is the actual utilization of these powers that improves the safety of devices on the market. There has been a decline in FDA enforcement actions, however. The issuance of warning letters declined by $50 \%$ between 2000 and 2005 , reaching a fifteen year low. ${ }^{167}$ The FDA center with the largest decrease was the Center for Devices and Radiological Health which, even in light of growing reports of device

162 IOM REPORT, supra note 6, at 135

163 William H. Maisel, 510(k) Premarket Notification Analysis of FDA Recall Data, in Public Health Effectiveness of the FDA 510(k) Clearance Process: Measuring Postmarket Performance and Other Select Topics: Workshop Report 73 (Theresa Wizemann ed., 2011).

164 Id. at 73-74.

165 Id. at 73.

166 Total Recalled Products by FDA Center Fiscal Year 2011, FDA.GOV, http://www.fda.gov/downloads/ICECI/EnforcementActions/ UCM285781.pdf.

167 U.S. HOUSE OF REPS. COMM. ON GOV'T REFORM - MINORITY

Staff SPECial Investigation Div., Prescription FOR HaRm: THE DECLINE IN FDA ENFORCEMENT ACTIVITY i (2006) [hereinafter DECLINE IN ENFORCEMENT], available at http://oversight-archive.waxman. house.gov/documents/ 20060627101434-98349.pdf. 
malfunctions during this period, issued $65 \%$ fewer warning letters in 2005 than $2000 .{ }^{168}$ This is an alarming statistic, particularly since reports have shown that the number of violations the FDA has observed during field inspections has remained fairly constant over the years. ${ }^{169}$

\section{b. Judicial}

If the administrative powers discussed above are not appropriate for a particular device, the FDA also has the authority to exercise a number of judicial enforcement powers. Section $304(\mathrm{~g})$ of the FDCA provides that the FDA can detain devices for up to thirty days if it has reason to believe the devices are adulterated or misbranded. ${ }^{170}$ The most common method for detaining products is seizure, which can occur anytime a suspected adulterated or misbranded device is in interstate commerce, held for sale, or any time after. ${ }^{171}$ The devices will be held until a condemnation decree is rendered by a court, at which point they may be destroyed as the court directs. ${ }^{172}$ Although this may be an effective way to prevent consumers from suffering harm from adulterated or misbranded devices, this enforcement action will not offer much help in protecting the public from unsafe devices cleared through the $510(\mathrm{k})$ process, because these actions do not reach products that may be injurious due to their design. ${ }^{173}$ In fiscal year 2011, the FDA's Center for Devices and Radiological Health seized only one device. ${ }^{174}$

The FDA also has the authority to seek injunctions. ${ }^{175}$

$168 I d$.

169 Id.

170 Inspections, Compliance, Enforcement, and Criminal Investigations - Administrative Detention of Devices, FDA.gov, http://www.fda.gov/ICECI/ComplianceManuals/RegulatoryProcedures Manual/ucm176980.htm (last visited Dec. 21, 2012).

17121 U.S.C. $\$ 334(a)(1)(2012)$.

17221 U.S.C. $\$ 334(d)(2012)$.

173 21. U.S.C. $\$ 334(\mathrm{a})(1)(2012)$.

174 Seizures by FDA Center Fiscal Year 2011, FDA.Gov, http://www.fda.gov/downloads/ICECI/EnforcementActions/UCM285781. pdf.

17521 U.S.C. $\$ 332(\mathrm{a})(2012)$. 
The FDCA provides that courts shall have jurisdiction, when cause is shown, to restrain violations of the FDCA. ${ }^{176}$ Injunctions can be sought for any significant failure to comply with FDA regulation, especially when the noncompliance has been identified as hazardous to health. ${ }^{177}$ This does not happen very frequently, however, and in fiscal year 2011, no injunctions were filed against any devices. ${ }^{178}$ The timeliness of the evidence presented in support of the injunction is critically important; the currentness of the information makes the action credible and limitations on the need to update the evidence are important. ${ }^{179}$ Courts will, in considering an injunction, evaluate the seriousness of the offense, the potential impact to the public, whether alternative corrective actions could be as effective as an injunction, and whether there is a likelihood of continued violation of FDA regulations in the absence of an injunction. ${ }^{180}$ Injunctions are best suited for situations where a definite health hazard or strong consumer deception with regard to the device exists, when recall or seizure is impractical, or when the noncompliant practices are long-standing and previously uncorrected by other means. ${ }^{181}$ Seeking an injunction does not preclude any of the other enforcement mechanisms available to the FDA. This enforcement mechanism will be helpful for $510(\mathrm{k})$ cleared devices rendered unsafe due to failures in GMP, labeling, or instruction, but it will not be helpful in removing devices found to be substantially equivalent to pre-1976 devices, because no regulations pertaining to

17621 U.S.C. $§ 332(\mathrm{a})$ (2012); see also 21 U.S.C. $§ 331$ (2012) (enumerating prohibited acts).

177 Inspections, Compliance, Enforcement, and Criminal Investigations - Injunctions, FDA.gov, http://www.fda.gov/ICECI/ ComplianceManuals/RegulatoryProceduresManual/ucm 176734.htm (last visited Dec. 21, 2012) [hereinafter Injunctions].

178 Injunctions by FDA Center Fiscal Year 2011, FDA.Gov, http://www.fda.gov/downloads/ICECI/EnforcementActions/UCM285781. pdf.

179 Injunctions, supra note 178.

180 Id.

181 Id. 
product design have been imposed which can be violated. ${ }^{182}$

Finally, the FDA is able to report violations to the Department of Justice (DOJ) for criminal prosecution. The FDCA provides penalties for violations of the act, including one year's imprisonment and/or fines up to $\$ 1,000$ for first time or unintentional violations, and three years imprisonment and/or a $\$ 10,000$ fine for intentional or repeated violations. ${ }^{183}$ Before a punishment of this nature may be imposed, due process requires that any potential defendant have notice and an op-portunity to present their own facts. 184 "The Office of Criminal Investigations (OCI) is responsible for reviewing all FDA matters for which a criminal investigation is recommended." 185 If, upon review of the all of the available information, the OCI decides that the request for a criminal investigation should be referred, it will be referred to the OCI's Office of the Chief Counsel, where documents will be prepared before being forwarded to the DOJ. 186

\section{When the Regulatory Process Fails: The Tort System}

The primary reason for the enactment of the FDCA and the MDA and the creation of the FDA was to protect consumers of medical drugs and devices. The FDA does not act alone in protecting consumers, however. The tort system also seeks to protect consumers of medical products by providing compensation to those harmed by defective products, as well as providing incentives for manufacturers

182 Compare Medical Devices: Premarket Approvals, U.S. FOOD AND DRUG ADMIN., http://www.fda.gov/MedicalDevices/ProductsandMedical Procedures/DeviceApprovalsandClearances/PMAApprovals/default.htm (last visited Nov. 26, 2012) with FDA, Medical Devices: Premarket Notification (510k), http://www.da.gov/medicaldevices/deviceregulationand guidance/howtomarketyourdevioe/premarketsubmissions/premarketnotification $510 \mathrm{k} /$ default.htm

18321 U.S.C. $\$ 333(\mathrm{a})(2012)$.

18421 U.S.C. $\S 335$ (2012).

185 Inspections, Compliance, Enforcement, and Criminal

Investigations - Prosecution, FDA.gov, http://www.fda.gov/ICECI/ ComplianceManuals/RegulatoryProceduresManual/ucm $176738 . \mathrm{htm}$ (last visited Dec. 21, 2012).

186 Id. 
to design safe products. ${ }^{187}$ The administrative and tort systems can work together to protect consumers; the FDA can impose a risk/benefit analysis before the product can go to market, setting a floor for product safety, and the tort system can incentivize manufacturers to make products increasingly more safe as new information makes improvements in product design or labeling reasonable. ${ }^{188}$

The ability of the tort system to help regulate the safety of medical devices can be difficult, however. The MDA contains an express preemption clause in $\S 360 \mathrm{k}$, which provides that:

[N]o State or political subdivision of a State may establish or continue in effect with respect to a device intended for human use any requirement--

(1) which is different from, or in addition to, any requirement applicable under this chapter to the device, and

(2) which relates to the safety or effectiveness of the device or to any other matter included in a requirement applicable to the device under this chapter. ${ }^{189}$

Section $360 \mathrm{k}$ raises many challenges to even bringing a suit that alleges a device is unsafe in any way, causing injury to the patient. The collaborative view of the FDA and the tort system has changed in recent years as pressure to increase innovation and bring more products to market has grown. ${ }^{190}$ Some believe that FDA regulation and review constitutes both a floor and a ceiling; that the tort system is counterproductive to ensuring consumer safety and that it deters manufacturers from developing much-needed new technologies due to a fear of tort liability. ${ }^{191}$ Furthermore, critics have also argued that lay juries are incapable of

187 Struve, supra note 106 , at 587.

188 Id.

18921 U.S.C. $\$ 360 \mathrm{k}$ (2012).

190 Struve, supra note 106 , at 587-88.

191 Id. at 588. 
understanding the scientific and statistical evidence that is relevant to determinations of a medical product's safety, and are consequently overly willing to help injured plaintiffs by overlooking the many other consumers who could benefit from the product. ${ }^{192}$ These perspectives have affected the decisions rendered by courts regarding the preemptive effect of the MDA's preemption clause.

The Supremacy Clause of the Constitution gives Congress the authority to pre-empt any state law that comes into conflict with the exercise of federal power. ${ }^{193}$ First it must be determined whether Congress explicitly intended to either preempt the state law claim, or leave the state law claim available. ${ }^{194}$ Such intention can be manifested in an express preemption or savings clause. ${ }^{195}$ As noted above, the MDA contains an express preemption provision, and therefore preempts state law. However, state law claims against product features that violate federal law will not be preempted because they are parallel to, and therefore not in conflict with, federal law. ${ }^{196}$

The Supreme Court has decided one case regarding a device that reached the market through the $510(\mathrm{k})$ process, finding the state tort claims were not pre-empted. In Medtronic, Inc. v. Lohr, the Court held that the MDA demands three things be present for preemption to apply: 1) a specific federal requirement 2) that applies to a specific medical device, and 3) which governs the safety and effectiveness of the device. ${ }^{197}$ Therefore, the MDA does not

192 Id.

193 U.S. CONST. art. VI, § 1, cl. 2.

194 Leflar \& Adler, supra note 16, at 710.

195 Id.; Cf. Victor E. Schwartz \& Cary Silverman, Preemption of State Common Law by Federal Agency Action: Striking the Appropriate Balance that Protects Public Safety, 84 TUL. L. REV. 1203, 1205-06 (2010) (explaining that Congress's intention to preempt state law may be implied through field preemption, which occurs when Congress expresses an intention to occupy an entire regulatory field and thereby leaves no room for state regulation).

196 Leflar \& Adler, supra note 16, at 714-15.

197 Medtronic, Inc. v. Lohr, 518 U.S. 470, 500 (1996); see also Donna B. DeVaney \& Patrick A. Hamiltyon, The 10,000 Pound Gorilla: Federal Preemption in Class III Medical Device Cases, 80 FLA.

B.J. 52, 54 (2006). 
preempt state common law defective design claims for devices which have gone to market through $510(\mathrm{k})$ premarket notification since allowing a monetary damages remedy does not impose additional "requirements" on the manufacturer, but rather provides the manufacturer with another reason to comply with the federal "requirements," namely, that the devices be reasonably safe and effective. ${ }^{198}$ Additionally, the Court found the manufacturing and labeling claims, in this instance, were not preempted. ${ }^{199}$ Since the state law labeling and manufacturing requirements apply to many different devices, they are laws of general applicability. ${ }^{200}$ Without specific federal requirements, there cannot be preemption of the state law claims because there is no conflict between federal and state requirements. ${ }^{201}$ In light of the Court's finding Lohr, the tort system remains available to help regulate the safety of $510(k)$ devices by offering financial awards for injured plaintiffs as well as financial incentives for manufactures to pro-duce safe devices. This shift of the source of pressure on the medical device industry, from the FDA to the tort system, to ensure the safety of medical devices makes sense in these circumstances, since the FDA plays a much smaller role in the regulation of $510(\mathrm{k})$ cleared devices. This is very different from the impact the tort system has on devices

198 Lohr, 518 U.S. at 495.

199 Id. at 498.

200 Id.

201 See generally 21 C.F.R. $\$ 801.430$ (2012) (stating that tampons must include labels describing the danger of Toxic Shock Syndrome); Nat'l Bank of Commerce v. Kimberly-Clark Corp., 38 F.3d 988, 990 (8th Cir. 1994) (holding the FDA's requirement that tampons include labeling that warns customers of the dangers of Toxic Shock Syndrome preempts state law); Natural Rubber-Containing Medical Devices; User Labeling, 62 Fed. Reg. 51021-01 (effective Sept. 30, 1997) (to be codified at 21 C.F.R. $\S 801.437$ ) (establishing the final rule of the FDA allergy warning requirements for latex gloves); FED. DRUG. ADMIN., ODE DOC. No. 1725, GUIDANCE FOR INDUSTRY AND FOOD AND DRUG Administration StafF - CONTACT Lens Care Products Labeling (Aug. 15, 2010), available at http://www.fda.gov/downloads/MedicalDevices/ DeviceRegulationandGuidance/GuidanceDocuments/UCM223665.pdf (discussing labeling and package insert requirements for contact lens solutions). 
which have received PMA.

The Supreme Court held that MDA preemption exists over claims that a device approved through the PMA process violates state law. In Riegel v. Medtronic, Inc., the Court found that the PMA process imposes "requirements" upon devices; requirements that are specific to each individual device granted approval.202 Consequently, the PMA process is a federal safety review of the device. ${ }^{203}$ State law claims would therefore be preempted if they imposed either additional requirements, or requirements that came into conflict with those imposed by the FDA. However, the Court found that the MDA's preemption provision does not prevent states from providing a damages remedy for parallel claims (claims premised on a violation of FDA regulations) since such claims do not add to federal requirements. ${ }^{204}$

Many people, including both patients and doctors, were unhappy with the Supreme Court's decision in Riegel granting broad preemption of state law design and warning claims, and feared it would have an adverse impact of the safety of medical devices. ${ }^{205}$ On March 5, 2009, the Medical Device Safety Act of 2009 was introduced into Congress. ${ }^{206}$ This Act would have added language to the MDA that would restore a plaintiff's ability to bring state law claims for injuries caused by defective medical devices, ${ }^{207}$ and have the effect of placing medical device claims on the same level as

202 Riegel v. Medtronic, Inc., 552 U.S. 312, 322-23 (2008); see also Medtronic, Inc. v. Lohr, 518 U.S. 470, 488-89 (1996) (interpreting the scope of the word requirement).

203 Riegel, 552 U.S. at 323 (cf. Lohr, 518 U.S. at 488).

204 Riegel, 552 U.S. at 330.

205 Gregory D. Curfman, Stephen Morrissey \& Jeffrey M. Drazen, The Medical Device Safety Act of 2009, 360 New ENG. J. MED. 1550, 1550-51 (2009) (stating that "[u]ntil [the Riegel ruling,] the possibility of litigation for 'failure to warn' or design defect served as a strong inducement for device companies to be vigilant about the safety of their products").

206 Medical Device Safety Act of 2009, H.R. 1346, 111th Cong. (2009) [hereinafter Medical Device Safety Act], available at http://www. govtrack.us/congress/bill.xpd?bill=h111-1346.

207 Id. 
pharmaceutical claims ${ }^{208}$ with regard to preemption. ${ }^{209}$ Although this Act received a lot of support, ${ }^{210}$ by the end of the $111^{\text {th }}$ Session of Congress it had not been passed and therefore was declared dead.211 It has not been reintroduced. ${ }^{212}$

\section{Proposals to Fix The Flaws In the System}

\section{A. Institute of Medicine: A New Regulatory System for $510(k)$ Devices}

In light of all of the issues already discussed surrounding the $510(\mathrm{k})$ process and the lack of pre-market evaluation of these devices for safety, proposals have been made to change the regulatory process and ensure device safety and effectiveness are evaluated on the front end, much as is the case for devices entering the market through the PMA process. Such changes will leave the FDA alone to regulate devices, however, due to the preemptive effect these determinations would have on state tort claims raised by injured plaintiffs. To address many of the safety concerns surrounding the $510(\mathrm{k})$ clearance process, the FDA asked the IOM to review the process and determine whether the process adequately protects patients and, if not, what legislative, regulatory, or administrative changes would optimally achieve the goals of the $510(\mathrm{k})$ process. ${ }^{213}$ The committee tasked with this evaluation is the Committee on Public Health Effectiveness of the FDA 510(k) Clearance

208 In Wyeth v. Levine, the Supreme Court reinforced the FDA's position that state law offers an important level of consumer protection that complements the effectiveness of the federal laws governing pharmaceuticals. Wyeth v. Levine, 129 S. Ct. 1187, 1202 (2009).

209 Support the Medical Device Safety Act!, MDSA CoALITION (Nov. 11, 2010), http://passmdsa.blogspot.com/2010/09/blog-post.html ("The bill will also reconcile the legal regime used for device manufacturers with the one used for drug manufacturers, in light of the Supreme Court's 2009 decision in Wyeth v. Levine.").

210 See id.

211 Medical Device Safety Act, supra note 206.

212 Id.

213 IOM Report, supra note 6, at 4. 
Process (CPHE). 214

The CPHE made a number of recommendations in their report to improve the $510(\mathrm{k})$ clearance process and, consequently, improve the FDA's regulation of these devices. The first conclusion drawn by the CPHE was that the $510(\mathrm{k})$ process is not intended to evaluate the safety or efficacy of devices, and cannot be transformed into such an evaluation as long as the standard for clearance remains substantial equivalence. ${ }^{215}$ In light of this finding, it recommended the design of a new regulatory framework enabling the $510(\mathrm{k})$ process to be replaced with a system that provides a reasonable assurance of safety and effectiveness throughout the device's life cycle. ${ }^{216}$ The new system would involve both pre-market and post-market regulation, and would rely on scientific evidence in reaching determinations of safety and effectiveness. ${ }^{217}$ Although the greater reliance on scientific evidence and clinical data might be similar to the PMA process, the proposed framework would focus most efforts instead on post-market surveillance of these devices, and in that way maintain both efficiency in the approval process while also ensuring the safety of these devices throughout their life cycle. ${ }^{218}$

Although this may sound like an effective way to solve the issues raised by the $510(\mathrm{k})$ clearance process, once practical concerns are addressed it becomes apparent that this recommendation will require much more than Congress passing new legislation to effectuate the desired changes. It cannot be forgotten that the FDA is an already overburdened agency with limited resources available to it. As pointed out above, $510(\mathrm{k})$ pre-market notification has been helpful to both the FDA and to the medical device industry because it offers a quicker way to bring devices to market which requires the filing of less information, and fewer hours of analysis, before clearance. Although it may be desirable to increase the depth of analysis under-taken
214 Id. at 16.
215 Id. at 193.
$216 I d$. at 196.
217 Id.
218 Id. at 197-99. 
by the FDA before these devices go to market, because of the FDA's limited resources, the likely effect will simply be a notable increase in the delay before the device actually comes to the market and becomes available to patients in need of these treatments. Medical tourism already occurs due to the delay in the approval of devices for market in the U.S. ${ }^{219}$ This effect is further exacerbated by manu-facturers considering marketing their devices only abroad, forgoing the U.S. market and FDA regulation entirely. ${ }^{220}$ Additionally, the "leniency" of medical device regu-lation in Europe, and its consequential speed and efficiency, have not demonstrated a resulting harm to patient safety, as evidenced by the almost equal rates of device recalls in the U.S. and Europe. ${ }^{221}$ Therefore, additional pre-market study and analysis will not necessarily assure the safety and efficacy of devices. But adding additional barriers before a device first reaches the market will harm both the med-ical device industry and American patients by increasing the time before the device is available.

219 I. Glenn Cohen, Protecting Patients with Passports: Medical Tourism and the Patient-Protective Argument, 95 IowA L. REV. 1467, 1471 (2010). Medical tourism describes the phenomenon by which patients of one country will choose to travel abroad to receive their medical care. There can be a number of reasons a patient would decide to engage in medical tourism. Oftentimes, patients who are uninsured or underinsured may choose to travel to countries offering the required treatment at a much more affordable price. Additionally, patients may be drawn to travel abroad because of the increased privacy the foreign locations offer. Most important to medical device regulation, however, are the occurrences in which patients who cannot access needed treatments in their home countries will travel abroad to receive treatment in countries which have a quicker or less regulated medical device market and access devices there which are not approved for the American market. See generally Andrew Pollack, Medical Treatment, Out of Reach, N.Y. TIMES, Feb. 10, 2011, at B1, http://www.nytimes. com/2011/02/10/business/10device.html?pagewanted=all (last visited Dec. 27, 2012).

220 Id.

221 ScotT Davis eT AL., EU Medical Device Approval Safety Assessment: A Comparative ANAlysis of MEdiCAL Device ReCALlS 2005-2009 9 (2011), available at http://www.commerce.gov/ sites/default/ files/documents/2011/july/report_european_us_medical_device_safety_0. pdf. 
Additionally, the CPHE called upon the FDA to improve the post-market performance surveillance of devices by improving its strategy for collecting, analyzing, and acting on device post-market performance information, and to make better use of its post-market regulatory authority. ${ }^{222}$ Recommendations were also made for the FDA to implement a continuous quality-improvement program and develop procedures to evaluate the safety and effectiveness of software used by devices as well. ${ }^{223}$ These measures will not alone be sufficient, however, to ensure the safety and efficacy of medical devices on the market today and in the future, as they raise new issues of their own.

Increasing the post-market surveillance efforts of the FDA after the devices have reached the market will similarly raise its own problems. Until the MDR databases can be improved, increasing reporting efforts and the depth of analysis of these reports will only be a daunting task for the FDA. Furthermore, until providers are better trained and more able to recognize effects caused by medical devices, efforts to increase reporting will not be effective. ${ }^{224}$ The voluntary reporting of information will only be as helpful as the completeness of the information reported, and until the databases can be integrated, enabling all relevant information about a medical device to be made available at once and analyzed together, the conclusions that can be drawn from a device's post-market performance will be limited.

The issues with the FDA's post-market surveillance efforts are not unique to $510(\mathrm{k})$ cleared devices. In the past decade, the FDA has seen an increase in the number of recalls of medical devices, as well as the number of adverse event reports, ${ }^{225}$ which has prompted the analysis of the sufficiency of post-market surveillance efforts. In early 2003, CDRH conducted an internal evaluation of postapproval studies, studies done on devices after they are

222 IOM Report, supra note 6, at 10.

223 Id. at $11-13$.

224 See MedSun, supra note 138.

225 Daniel Schultz, Medical Device Safety: FDA's Postmarket Transformation Initiative, 62 FooD \& DRUG L.J. 593, 593 (2007). 
approved for marketing under the PMA process, and found that this process overall did not perform as expected, and that this post-market surveillance tool and oversight both needed to be improved. ${ }^{226}$ Congress has also recognized the issues with post-market surveillance, and in 2002 directed $^{227}$ the Secretary of HHS to study the effects of the medical device user fee program on post-market surveillance, and instruct the Institute of Medicine (IOM) to study whether the post-market surveillance system of medical devices provides adequate safeguards regarding the use of devices in pediatric patients. ${ }^{228}$ In the IOM's resulting report, general shortfalls in the FDA's entire postmarket surveillance process were recognized. ${ }^{229}$ The IOM identified "[t]he most obvious deficits in FDA's performance are the agency's lack of effective procedures for monitoring the status of required post-market studies and the lack of public information regarding such studies." 230 Furthermore, the FDA's authority to order post-market studies is limited. Studies cannot be required as a condition of approving devices through the PMA process, and for devices already granted PMA approval; the FDA cannot require postmarket studies that will last more than three years. ${ }^{231}$

\section{B. Use of Comparative Effectiveness Research by the Government as Payer}

The limits which constrain the FDA's regulatory

226 Danica Marinac-Dabic et al., Medical Devices Post-Approval Studies Program: Vision, Strategies, Challenges and Opportunities, 62 FOOD \& DRUG L.J. 597, 598-99 (2007).

227 Medical Device User Fee and Modernization Act of 2002, Pub. L. No. 107-250 107th Cong. (2002), available at http://www.fda.gov/ regulatoryinformation/legislation/federalfooddrugandcosmeticactfdcact/ significantamendmentstothefdcact/medicaldeviceuserfeeandmodernizati onactmdufmaof2002/default.htm.

228 Marinac-Dabic, supra note 226, at 598-99.

229 INST. OF MED., SAFE MEDICAL DEVICES FOR CHILDREN 5 (Marilyn J. Field \& Hugh Tilson eds., 2005), available at http://books.nap.edu/ openbook.php?record_id=11313\&page=R1.

$230 \quad$ Id. at 6.

231 Id. at 7. 
activities are caused primarily by the limited resources and funding available to the FDA to carry out its activities. Although the FDA is certainly making an effort to work effectively even within these constraints, the effects are evident not merely in the outcomes achieved by the FDA, but also in the performance goals it sets for itself. For example, in 2008 the FDA set a performance goal to review $60 \%$ of original PMA applications in 180 days and $90 \%$ in 295 days. ${ }^{232}$ This goal was not met in 2008, but was exceeded in 2009. However, in recent years, the FDA decreased its performance goal. ${ }^{233}$ The 2012 bud-get report predicted "[i]f the number of reviewers remains constant, $\mathrm{CDRH}$ expects performance levels to decrease due to the increasing complexity of PMAs."234 The goals for review of $510(\mathrm{k})$ applications have similarly been lowered in recent years, from $90 \%$ in ninety days and $98 \%$ in 150 days in 2010 to $75 \%$ in ninety days and $80 \%$ in 150 days for 2012.235 The FDA explained, "[i]f the number of reviewers remains constant, CDRH expects performance levels to decrease."236 On the plus side, the FDA's goals for the number of Class II and Class III device inspections, both domestic and foreign, have been increasing each year since 2008, and have been exceeded each year for which information is available. ${ }^{237}$

To improve the FDA's ability to adequately exercise its authority and ensure the safety of the products it regulates, a budget increase would go a long way in alleviating the burdens the agency already experiences through its limited re-sources and manpower. Consequently, the FDA is

232 Dep'T Health \& Human Servs., Food \& Drug Administration: FY 2012 ONLINE PERFORMANCE APPENDIX 42 (2012), available at http://www.fda.gov/downloads/AboutFDA/ReportsManualsForms/ Reports/BudgetReports/UCM242730.pdf.

$233 I d$. at 42 (decreasing the performance goal to $50 \%$ in 180 days and $70 \%$ in 295 days in 2011, and 50\% in 180 days and $60 \%$ in 295 days for 2012).

234 Id. at 47.

235 Id. at 42.

236 Id. at 47.

237 Id. at 44 . In 2008, the goal of 1,270 inspections was exceeded with a total of 1,431 inspections that year. The goals have been increased to 1,365 in 2012 (exceeded with 1,659 inspections that year), and 1,515 for 2012 . 
requesting a $17 \%$ increase in its budget as part of President Obama's fiscal year 2013 budget. ${ }^{238}$ The majority of this increase would, under the proposal, come from industry user fees (such as application and inspection fees), which would account for $98 \%$ of this increase. ${ }^{239}$ In previous years, about one third of the FDA's budget was funded through user fees; under the new proposal, however, this amount would be increased to $45 \% .{ }^{240}$ Federal spending on the FDA would be increased by only $0.5 \% .^{241}$ This new budget plan would bring the FDA's total budget to $\$ 4.5$ billion. ${ }^{242}$ However, the FDA does not yet have cause to celebrate; Obama's proposed budget plan must be approved by Congress before it can be effective. Debates over spending cuts, tax hikes, and resource allocation could easily stall this budget plan before the FDA gets a chance to benefit from any of the proposed measures. ${ }^{243}$

One important way the safety and efficacy of devices can be ensured without increasing the burdens on an already overwhelmed FDA is through assigning to another agency or department the task of increasing the study and surveillance of medical devices. This can be done postmarket, and therefore would not infringe on the FDA's authority, but instead would complement the FDA's postmarket surveillance efforts. Consumers and payers can also have an impact on the safety and efficacy of products available on the market. This can be done through the use of comparative effectiveness research (CER) in payer decisions to cover available devices, and can have the most

238 FDA News Release: FDA Seeks $\$ 4.5$ Billion to Support Medical Product Development, Protect Patients and Ensure Safety of the Food Supply, FDA.gov (Feb 13, 2012), http://www.fda.gov/newsevents/ newsroom/pressannouncements/ucm291691.htm [hereinafter FDA News Release] (covering the period from Oct. 1, 2012 through Sept 30, 2013).

239 Id.

240 Anna Yukhananov, Obama Asks for Hike in Industry Funding for FDA, REUTERS, (Feb. 13, 2012), http://www.reuters.com/article/2012/ 02/13/us-budget-fda-idUSTRE81C24O20120213.

241 Id. Total federal spending on the FDA under this proposed budget would be $\$ 2.5$ billion for FY 2013 .

242 FDA News Release, supra note 238.

243 Yukhananov, supra note 240. 
impact on the device market if the largest payer is able to make use of comparative effectiveness research in their coverage deter-minations: the government.

The U.S. spends over $\$ 2$ trillion on health annually. ${ }^{244}$ Only about $5 \%$ of the U.S.'s overall health expenditures are devoted to research, and the vast majority of this goes to product development and basic research, not into assessing the effectiveness or outcomes of treatment options. ${ }^{245}$ The first goal, therefore, should be to increase the amount of comparative effectiveness research being conducted. Once helpful information has been gathered, it can be used by payers to incentivize the use of the most safe and effective devices available, thereby improving the care given to patients and helping to keep unsafe or ineffective devices cleared for the market without pre-market analysis or approval from being used in common medical practice until they are proven to be safe and effective, or at least as safe and effective as alternative treatments available.

First, some background about CER may be helpful. Studies focusing on the efficacy of a device, the extent to which the device will produce a beneficial result, are known as clinical effectiveness studies. ${ }^{246}$ These studies may consider the use of the device under ideal circumstances, or its use under ordinary circumstances (which usually involves a broadening of the delivery settings, patient populations, or avail-ability of alternative therapies in their analyses).247 Results from multiple studies can be accumulated and assessed as a group, to enable conclusions of effectiveness to be drawn that will have sufficient weight to be reasonably used in practice. ${ }^{248}$

The most effective use of the information obtained through these clinical effectiveness studies, however, is in

244 INST. OF MED., LEARNING WHAT WORKS BesT: THE NATION'S NEED FOR EVIDENCE ON COMPARATIVE EFFECTIVENESS IN HEALTH CARE 6 (2007), available at http://www.iom.edu/ /media/Files/Activity\% 20Files/Quality/VSRT/ComparativeEffectivenessWhitePaperESF.pdf [hereinafter IOMCE].

245 Id. at 2.

246 Id. at 7 .

247 Id.

$248 I d$. 
comparing the effectiveness of alternative treatment options against each other to provide information about the relative outcomes of the interventions, and which will be most likely to produce the best patient outcome in different circumstances. ${ }^{249}$ This is known as comparative effectiveness research, or CER. Many experts recommend using the metric of "quality adjusted life-years" as the standard for measuring health outcomes. ${ }^{250}$ This metric would signify the effects of treatments in terms of gains or losses in time spent in any of a number of quality-weighted health statuses. In this way, the metric would enable a simple comparison of multiple treatment options over a range of patient conditions and diseases. ${ }^{251}$ The utility and relative merits of different interventions (not limited to devices, but also diagnostic tests or surgical, pharmaceutical, or de-vice treatment options) can be obtained through the CER can be directly compared, enabling inferences to be drawn on the likelihood each has of achieving the best patient outcome possible. ${ }^{252}$

CER is not a new concept, and in fact research has been carried out in the U.S. for years, primarily under the auspices of the National Institutes of Health (NIH), the Agency for Healthcare Research and Quality (AHRQ), and the Department of Veterans Affairs. ${ }^{253}$ Additionally, the FDA, the Centers for Disease Control, ${ }^{254}$ and other HHS agencies have for years been contributing to CER. ${ }^{255}$ The basic information collected by the FDA regarding the safety

249 Id. at 7-8.

250 Peter J. Neuman \& Milton C. Weinstein, Legislating Against Use of Cost-Effectiveness Information, 363 NEW ENG. J. MED. 1495, 1495 (2010).

251 Id.

252 IOM CE, supra note 244 , at 8

253 John Donnelly, Health Policy Brief: Comparative Effectiveness Research, HEALTHAFFAIRS (Oct. 8, 2010), http://www.healthaffairs.org/ healthpolicybriefs/brief.php?brief_id=27 (last visited Dec. 27, 2012).

254 IOM CE, supra note 244, at 9. The CDC funds research used in public health decision services and systems, some which examines the effectiveness of some infectious disease therapies or vaccines, and maintains a number of national data systems containing information important for certain types of clinical effectiveness studies.

255 Id. 
and efficacy of products for which PMA is required, as well as the information collected post-market through adverseevent reporting and other surveillance has been used in these efforts, and the Sentinel Network previously discussed will further help in this respect. ${ }^{256}$ It is important to note that the FDA does not require information of the comparative effectiveness of any product in order to grant approval; however, information specific to the product of its effectiveness for its indicated use is required for PMA. ${ }^{257}$

Additionally AHRQ, through a mandate contained in the Medicare Prescription Drug, Improvement, and Modernization Act, ${ }^{258}$ performs research focusing on patient outcomes, the appropriateness of treatments, and the comparative effective-ness of treatments. In carrying out this mandate, AHRQ created the Effective Health Care Program that makes use of existing research to create Comparative Effectiveness Reports, identify areas lacking in information about treatment effect-tiveness, and improve the delivery of the results found to providers and others. ${ }^{259}$ National interest in CER has risen over the years, a likely result of the increasing costs of healthcare. The American Recovery and Reinvestment Act allocated $\$ 1.1$ billion for conducting CER. ${ }^{260}$ Additionally, the Patient Protection and Affordable Care Act (ACA) created the Patient-Centered Outcomes Research Institute (PCORI) to conduct comparative effectiveness research. ${ }^{261}$

The use of CER in healthcare is not unique to the U.S. either, and in fact has been used by many other countries for years, both in coming up with clinical practice guidelines

256 Id.

257 See Premarket Approval of Medical Devices, 21 C.F.R. $\S$ 814.20(b)(3)(v)-(vi) (2012).

258 Medicare Prescription Drug, Improvement, and Modernization Act of 2003, Pub. L. 108-173 Stat. 2066 (2003) (codified in 42 U.S.C. $\S$ 299(b)-(7) (2012)).

259 IOM CE, supra note 244 , at 9 .

260 Recovery Act Allocates $\$ 1.1$ Billion for Comparative Effectiveness Research, HHS.GOV, http://www.hhs.gov/recovery/ programs/os/cerbios.html (last visited Dec. 2, 2012).

261 Patient Protection and Affordable Care Act, Pub. L. No. 111-148 $\S 1181(b), 124$ Stat. 119 (2010). 
as well as in making coverage determinations for government health plans. The uses of CER among these countries share some common traits, which the U.S. can learn from in making the best use of its own comparative effectiveness information. One important commonality among nations is the independence of the entities responsible for making comparative effectiveness recommendations have from the government. ${ }^{262}$ Although many are created and/or funded by the nation's government, the entities operate independently and include all stakeholders in the decision-making and methodology design processes. ${ }^{263}$ Additionally, most of these entities have been able to gain stakeholder support by including all stakeholders, especially manufacturers, in the design of the program and the decision-making process, ${ }^{264}$ and making much of the information relied upon in making comparative effectiveness determinations available to the public. ${ }^{265}$ This will be important in not only ensuring the decisions reached will have con-sidered all sides of an issue, but also ensuring the affordability and completeness of information upon which decisions can be based, since the sector with the best capacity to generate and apply comparative effectiveness information is the manufacturing sector. ${ }^{266}$ Establishing an appeals process by which comparative effectiveness decisions may be challenged by interested parties will also be important in gaining support from stakeholders and the public, as well as ensuring decisions are accurate based on

262 KaLIPSO CHALKIDOU \& GERARD ANDERSON, COMPARATIVE EFFECTIVENESS RESEARCH: INTERNATIONAL EXPERIENCES AND IMPLICATIONS FOR THE UNITED STATES 3 (2009), available at http://www.academyhealth.org/files/publications/CER_International_ Experience_09\%20(3).pdf.

263 Id. at 3-4.

264 Id. at 3.

265 See id. at 3. For example, the United Kingdom's National Institute for Clinical Excellence, makes all information upon which its decisions are based available to the public. All confidential information is carefully scrutinized by the Institute, and it encourages the sources of such confidential information to make it available to the public as soon as possible.

266 IOM CE, supra note 244 , at 5. 
the data available at the time. ${ }^{267}$

Another important quality common among these countries is the modest budget and small number of people needed to operate the entities responsible for drawing conclusions from and making recommendations based on CER. ${ }^{268}$ Most of these entities require only a few hundred employees to effectively carry out their duties, and have operating budgets of less than $\$ 60$ million. ${ }^{269}$ To make these benefits possible, many of the entities rely on other bodies to conduct the research necessary to arrive at their conclusions, ${ }^{270}$ much as AHRQ and PCORI are already able to make use of research conducted through other government entities and the private industry (made available through FDA filings and reporting). This supports the prediction that charging another office or agency of the government with analyzing clinical effectiveness research of medical devices and arriving at comparative effectiveness determinations will be an affordable alternative way to ensure adequate post-market surveillance of $510(\mathrm{k})$ cleared devices, while also alleviating the burdens the FDA already faces in carrying out its other duties. Furthermore, this will provide additional incentives for the medical device industry to comply with federal regulations, which could potentially improve compliance even in light of the FDA's budgetary constraints and the recent reduction in FDA enforcement actions. ${ }^{271}$

However, providers and patients alike expressed concern that the information gained from CER would be used to limit and deny coverage to patients who value the tradeoff between extending their life and the risk of disability differently than the government might. Consequently, the $\mathrm{ACA}$, in an effort to alleviate these fears, expressly prohibited the use of CER findings to discourage anyone from choosing a particular treatment or therapy. ${ }^{272}$

\footnotetext{
267 CHALKIDOU, supra note 262 , at 4.

268 Id. at 3.

$269 I d$.

$270 I d$.

271 See Decline in Enforcement, supra note 167, at i.

272 Patient Protection and Affordable Care Act, Pub. L. No. 111-148, $\S 1182(\mathrm{~d}), 42$ U.S.C. $§ 1320(\mathrm{e})(1)(2010)$.
} 
Specifically, the ACA states:

(d)(1) The Secretary shall not use evidence or findings from comparative clinical effectiveness research conducted under section 1181 in determining coverage, reimbursement, or incentive programs under title XVIII in a manner that precludes, or with the intent to discourage, an individual from choosing a health care treatment based on how the individual values the tradeoff between extending the length of their life and the risk of disability.

(2)(A) Paragraph (1) shall not be construed to-

(i) limit the application of differential copayments under title XVIII based on factors such as cost or type of service; or

(ii) prevent the Secretary from using evidence or findings from such comparative clinical effectiveness research in determining coverage, reimbursement, or incentive programs under such title based upon a comparison of the difference in the effectiveness of alternative health care treatments in extending an individual's life due to that individual's age, disability, or terminal illness. ${ }^{273}$

The best way to ensure that patients receive the best possible care, and the most effective way to ensure the safety and effectiveness of devices cleared through the $510(\mathrm{k})$ process, however, is to enable the government to make use of comparative effectiveness information in their coverage decisions just as private insurers do, and consequently, the prohibition on the use of this information in coverage decisions should be lifted.

Concerns have been raised that the use of CER to 
deny coverage will open the doors to the making of coverage decisions not on the patient's health outcome, but on the perceived value to society of the healthcare dollars spent, as measured by the patient's anticipated subsequent level of productivity in society. ${ }^{274}$ Arguments supporting CER point out that true healthcare savings will result from changing how doctors think about healthcare, ${ }^{275}$ and remembering that providing all available treatments is not necessarily in the patient's best interest nor will it necessarily lead to the best patient outcome. These arguments, however, have been met with opposition fueled by the fear that the result will be the denial of care to elderly or disabled patients, and patients will be discriminated against in the provision of

274 Sarah Palin, Statement on the Current Healthcare Debate, FACEBOOK (Aug. 7, 2009), https://www.facebook.com/note.php? note_id=113851103434 ("The Democrats promise that a government health care system will reduce the cost of health care, but as the economist Thomas Sowell has pointed out, government health care will not reduce the cost; it will simply refuse to pay the cost. And who will suffer the most when they ration care? The sick, the elderly, and the disabled, of course. The America I know and love is not one in which my parents or my baby with Down Syndrome will have to stand in front of Obama's 'death panel' so his bureaucrats can decide, based on a subjective judgment of their 'level of productivity in society,' whether they are worthy of health care. Such a system is downright evil.").

275 See, e.g., Ezekiel J. Emanuel \& Victor R. Fuchs, The Perfect Storm of Overutilization, 299 JAMA 2789, 2790-91 (2008) ("When evaluating a patient, students, interns, and residents are trained to identify and praised for and graded on enumerating all possible diagnoses and tests that would confirm or exclude them. The thought is that the more thorough the evaluation, the more intelligent the student or house officer. Trainees who ignore the improbable 'zebra' diagnoses are not deemed insightful. In medical training, meticulousness, not effectiveness, is rewarded. This mentality carries over into practice. Peer recognition goes to the most thorough and aggressive physicians. The prudent physician is not deemed particularly competent, but rather inadequate. This culture is further reinforced by a unique understanding of professional obligations, specifically, the Hippocratic Oath's admonition to 'use my power to help the sick to the best of my ability and judgment' as an imperative to do everything for the patient regardless of cost or effect on others. . . Rapid reforms of medical education and training, even when widely acknowledged as essential, are uncommon. ... Realistically, the most effective policy change would be to alter how insurance pays for medical services."). 
healthcare based on their age or health status. ${ }^{276}$ This is not at all the use of CER presented in this article, however. CER would be used not to deny all medical treatment for a patient, but rather to provide an incentive for healthcare providers to pursue the treatment options that will present the best possible clinical outcome for the patient. CER by definition involves the comparison of one treatment option to another in an effort to determine which of the two will achieve the best outcomes for patients with the studied illnesses or conditions. Decisions to pursue a treatment option will be based not on the doctor's perception of the value to society that his particular patient presents, but instead on the potential that available options have to successfully treat the patient, based on sound clinical evidence.

If a particular medical device is found through CER to be unable to give the patient a chance to achieve a better health outcome than another device, drug, or surgery may, then coverage of that treatment option would be denied under this article's proposal. The patient would still have the choice to pursue that treatment option if he wants to pay out of pocket for the costs (just as medical tourism presents this option to patients now),277 but the use of treatment options found through clinical evidence to be safer and to lead to better healthcare outcomes would be incentivized. In this way, the necessary post-market surveillance the FDA does not have the resources to conduct will be undertaken by an agency of the government with the resources and manpower to effectively monitor the devices. Additionally, concerns raised by the industry and patients that further regulation will dampen innovation and further delay the availability of devices in the U.S. market will

276 See, e.g., Michele Bachmann, The President's Health Care Advisers, YouTUBE (July 31, 2009), http://www.youtube.com/ watch? $=5$ CHBvKGmevI (arguing that the health reform bill would result in the inclusion into a doctor's healthcare decision-making process considerations of whether the healthcare dollars "would be better spent on someone else," reserving medical care for only those patients who are non-disabled; who have not yet been irreversibly prevented from participating in society).

277 See Cohen, supra note 219, at 1489. 
never be realized, because devices will still be cleared for marketing through the quicker process and remain available to patients ${ }^{278}$ even if government payers later determine, based on subsequently conducted CER, not to cover certain devices in certain circumstances.

Furthermore, the government will have enough leverage to effectively incentivize the medical device industry to improve the safety and efficacy of their devices. As already mentioned, overall the U.S. spends over $\$ 2$ trillion on health annually, about $45 \%$ of these expenditures made by the government. 279 This figure includes all expenditures made under the Medicaid and Medicare programs, as well as expenditures made for the Veterans Health Administration, Indian Health Service, and Federal Employees Health Benefit Plan. ${ }^{280}$ The government constitutes a large share of the payer market. Medical device companies, understandably profit driven, will be much more inclined to put forth the effort to ensure their devices are safe and effective enough to qualify for coverage under government health programs than they would by coverage determinations of individual private insurers, which each cover a much smaller share of the patient market.

Limiting the devices covered under the government programs is not likely to result in harm to patient outcomes either. The U.S. spends more on healthcare than any other country, with per capita expenditures double that of European countries and at least 20\% higher than every other country. ${ }^{281}$ Even with all of this spending on healthcare, the U.S. ranks are well below other countries in terms of health outcomes. The U.S. ranks twenty-eighth in the world for overall life expectancy at birth. ${ }^{282}$ Specifically, the average life expectancy in the U.S. at birth in 2009 was

278 Patients will still have the option to pay out of pocket for any treatments not covered by their insurer.

279 IOM CE, supra note 244 , at 6.

280 Id. at 2.

281 Id. at 3.

282 Id. at 1. 
seventy-six years for men and 80.9 years for women. ${ }^{283} \mathrm{By}$ comparison, the life expectancies in the United Kingdom were seventy-eight years and 82.2 years, ${ }^{284}$ for France 77.8 and 84.8 years, ${ }^{285}$ and for Japan (with the world's longest life expectancy ${ }^{286)} 79.6$ and 86.5 years, ${ }^{287}$ respectively.

Variations in healthcare service utilization are prevalent within the U.S. as well. It has been found that intensity of services for similar conditions can vary by as much as a factor of twenty, and achieve similar results. ${ }^{288}$ Even within the U.S. studies comparing the different healthcare spending rates between regions found that patients of the highest spending hospitals were $2-6 \%$ more likely to die than patients receiving care at the lowest spending hospitals. ${ }^{289}$ All of this evidence shows that higher spending and higher utilization of healthcare does not mean better health. Quite the contrary, advances in medical technologies result in an increase in the treatments available to patients, and a widening of the eligibility criteria for already available procedures and treatments, ${ }^{290}$ which can lead to greater utilization without a notable improvement in patient outcome. ${ }^{291}$

283 Global Health Observatory Data Repository: United State of America, Country Statistics, WORLd HEALTH ORGanization (2011), http://apps.who.int/ghodata/?theme=country (last visited Dec. 2, 2012).

284 Global Health Observatory Data Repository: United Kingdom, Country Statistics, WORLD HEALTH ORGANIZATION (2011), http:// apps.who.int/ghodata/?theme=country (last visited Dec. 2, 2012).

285 Global Health Observatory Data Repository: France, Country Statistics, WORLD HEALTH ORGANIZATION (2011), http://apps.who. int/ghodata/?theme=country.

286 See Howard Steven Friedman, 5 Countries with the Longest Life Expectancy: OECD, HuffingtonPost.com (May 27, 2011) http:// www.huffingtonpost.com/howard-steven-friedman/lifeexpectancy_b_867361.html\#s284378\&title=5_Sweden_814.

287 Global Health Observatory Data Repository: Japan, Country Statistics, WORLD HEALTH ORGANIZATION (2011), http://apps.who. int/ghodata/?theme=country.

288 IOM CE, supra note 244 , at 1.

289 Shannon BRownleE, OvertReated: Why TOO Much MEdicine IS MAKING US SICKER AND POORER 50 (2007).

290 Ruud ter Meulen, Is Rationing the Inevitable Consequence of Medical Advance?, 27 MED. \& L. 71, 75 (2008).

291 BROWNLEE, supra note 289, at 113. 
Even in light of all of these facts, it may be easy to wonder why devices should have a separate approval process at all. The FDA regulates pharmaceutical drugs as well as medical devices; perhaps efficiencies could be created within the agency itself by using a single regulatory pathway by requiring all medical devices to go through the full PMA process, like pharmaceuticals must. This would not be the answer, however, because there are significant differences between drugs and devices. For one thing, drugs have longer product life cycles than devices do. ${ }^{292}$ This is because drugs are not likely to change over time, since changes in the molecular structure of the drug creates an entirely new drug that needs independent FDA approval. In contrast, devices commonly experience incremental changes over time, and often the technology changes rapidly. ${ }^{293}$ This constrains the possibility of conducting long-term premarket studies due to the likelihood the device will change, and consequently makes it difficult to study, or even detect, risks that emerge slowly from device use. ${ }^{294}$ Furthermore, drugs may be used by potentially millions of consumers, while devices are used by a comparatively small number of patients. ${ }^{295}$ The limited number of device users impedes the ability of researchers to conduct randomized controlled studies in an effort to detect rare adverse events or differences in effectiveness between products. ${ }^{296}$ It is precisely because of these differences that devices must be regulated differently from pharmaceuticals, and why Congress passed legislation crafting two different regulatory frameworks. ${ }^{297}$

While accepting the need to regulate devices differently from pharmaceuticals, the argument can still be made that all devices should be required to undergo the more intensive PMA process and the $510(\mathrm{k})$ clearance should be eliminated altogether, in the belief that this would ensure medical

\footnotetext{
292 IOM Report, supra note 6, at 17.

$293 I d$

$294 I d$.

$295 I d$.

$296 I d$

297 Id. at $17-18$.
} 
devices are safe before they ever reach the market. As already discussed, there has been debate about the proper balance the FDA must strike between ensuring adequate evaluation of devices before being approved for market, and the need of patients to have timely access to new medical technologies as they are developed. Although the sufficiency of the $510(\mathrm{k})$ clearance process has been questioned for years, it is obvious that the process enables medical device companies to get their devices to market more quickly than PMA review. However, the more intensive PMA process has been criticized by many in the medical device industry as hurting innovation and causing the U.S. medical device industry to lose its competitive edge overseas. ${ }^{298}$ Patients are harmed by these effects as well, since many medical device companies are now choosing to seek approval for new devices in Europe first due to the speed with which the device can be approved for market. The difference can be quite significant; a heart valve able to be installed through a catheter, saving the patient from undergoing open-heart surgery, was approved in Europe more than three years earlier than in the U.S. ${ }^{299}$

There are a number of differences between the review and approval processes for medical devices in the U.S. and Europe. The European Union's device regulation system is governed by three directives: the Medical Device Directive, ${ }^{300}$ the In-Vitro Diagnostic Directive, ${ }^{301}$ and the Active Implantable Medical Device Directive. ${ }^{302}$ Each lays out guidelines for the approval of their respective devices, and contains a list of Essential Requirements that must be met by each product within its scope, requirements that can

298 Pollack, supra note 219.

299 Id.

300 Eur. Consult. Ass., Council Directive 93/42/EEC (June 14, 1993), available at http://www.emergogroup.com/files/EUROPECONSOLIDATED-MDD-93-42-EEC.pdf.

301 Eur. Consult. Ass., Council Directive 98/79/ED (Oct. 27, 1998), available at http://www.emergogroup.com/files/In-Vitro-DiagnosticsDirective-98-79-EC-v2.pdf.

302 Eur. Consult. Ass., Council Directive 90/385/EEC (June 20, 1990), available at http://www.emergogroup.com/files/EUROPECONSOLIDATED-90-385-EEC.pdf. 
be generally classified as either general requirements for safety and performance applicable to all devices, ${ }^{303}$ or specific technical design and manufacturing requirements applicable to certain types of devices. ${ }^{304}$

The approval system operates in a decentralized fashion, as countries coordinate their own approval system in accordance with the directives. Each country's Competent Authority certifies for-profit "Notified Bodies," which are then authorized to approve a broad variety of goods for market, including medical devices. ${ }^{305}$ These bodies will accept and certify new device applications, and may request clinical data or other information, or may perform manufacturing quality assessments in making its determination. ${ }^{306}$ Currently, there are seventy-eight notified bodies, among thirty countries, authorized to grant certification and approve medical devices for marketing in the European Union. 307 The medical device approval process in the European Union is typically completed about twentyone months sooner than in the U.S. ${ }^{308}$

Critics have countered with the argument that it is not that the FDA's regulations are too stringent, but rather, the European Union's regulation of medical devices is too

303 See Eur. Consult. Ass., Medical Device Directive, Article 3 and Annex 1 (June 14, 1993), available at http://www.emergogroup.com/ files/EUROPE-CONSOLIDATED-MDD-93-42-EEC.pdf.

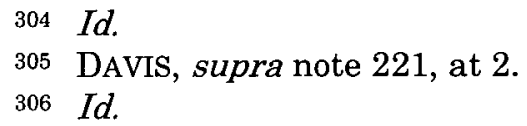

307 Enterprise and Industry: Nando, Bodies, EUROPEAN COMMISSION, http://ec.europa.eu/enterprise/newapproach/nando/index. $\mathrm{cfm}$ ?fuseaction=directive.notifiedbody\&dir_id=13\&type_dir=NO\%20CPD\& pro_id=99999\&prc_id=99999\&ann_id=99999\&prc_anx=99999 （last visited Dec. 2, 2012).

308 Todd V. Dhavale, Evaluation of the Medical Device APPROVAL LAG BETWEEN THE UNITED STATES AND THE EUROPEAN UNION 35 (2011), available at http://dspace.mit.edu/ handle/1721.1/68465. In a study of twenty years of approval data for 135 coronary stent, ICD and spine Class III medical devices, it was found that the total average approval lag for these devices in the United States was over twenty-one months behind the European Union. Of the 135 devices studied, thirtyfour were approved in the European Union but not yet approved in the United States. 
lenient. 309 For example, "a breast implant, a lung sealant and an implant for elbow fractures were approved in Europe but not in the U.S., and then had to be taken off the market in Europe for safety reasons." 310 Although re-calls have in fact occurred, studies suggest the rates of recalls in Europe and the U.S. are quite similar. One study found that the overall number of annual recalls of devices between 2005 and 2009 was very similar between the U.S. and Europe, hovering around 21.311 The study found that for the U.S., $45 \%$ of the recalls related to pre-market issues while $55 \%$ related to post-market issues. ${ }^{312}$ To compare, the rates for Europe were $46 \%$ and 54\%, respectively. ${ }^{313}$ These findings suggest that the faster approval processes used in Europe does not sacrifice patient safety.

\section{CONCLUSION}

It is apparent that the $510(\mathrm{k})$ clearance process does not sufficiently protect patients from unsafe medical devices. Although creating a new regulatory framework involving more pre-market and post-market regulation and relying on scientific evidence in reaching determinations of safety and effectiveness is one possible way to improve device regulation, the feasibility of this method is limited due to the inability of the FDA's current resource constraints. Instead, the best way to ensure the safety and efficacy of medical devices is for the federal government, in its capacity as payer, to use CER of medical devices entering the market. This information would be used by these federal programs in determining whether or not devices will be covered, and will alleviate the burdens on the FDA by shifting the responsibility for this increase post-market

309 Pollack, supra note 219. Other examples of devices approved in Europe but not available in the United States include artificial disks for spines.

$310 \mathrm{Id}$

311 DAVIS, supra note 221, at 9.

312 Id. at 7.

313 Id. 
study and surveillance of $510(\mathrm{k})$ devices from the FDA to other federal agencies. In this way, the U.S. will foster innovation and maintain a competitive market in the medical device industry, without sacrificing patient safety through this more efficient approval process. Healthcare providers will likewise benefit from this proposal, as additional research is still conducted regarding the comparative effectiveness of new devices, and this information will be available to guide medical decision making and ensure patients receive the safest and most effective treatments available. 
